\title{
The FDA And ABCs: Unintended Consequences Of Antidepressant Warnings On Human Capital ${ }^{\star}$
}

\author{
Susan H. Busch, Ezra Golberstein, and Ellen Meara
}

\section{Abstract}

Using annual cross-sectional data on over 100,000 adolescents aged 12-17, we studied academic and behavioral outcomes among those who were and were not likely affected by FDA warnings regarding the safety of antidepressants. Compared to other adolescents, adolescents with probable depression experienced a relative decline in grade point average of .14 points following the FDA warnings. The FDA warnings also coincided with increased delinquency, use of tobacco and use of illicit drugs. Together, our results stress the importance of mental health and its treatment as an input into cognitive and non-cognitive aspects of human capital.

\begin{abstract}
A burgeoning theoretical and empirical literature argues that compared with cognitive aspects of human capital that raise individual productivity, "non-cognitive" aspects of human capital are equally important. Empirical evidence links varied non-cognitive characteristics, ranging from measured hyperactivity, anxiety, locus of control, and self esteem in childhood to later wages, income, and social outcomes (Blanden et al. 2006; Borghans et al. 2008; Bowles et al. 2001; Currie and Stabile, 2009; Heckman et al. 2006). A universally agreed upon construct of non-cognitive dimensions of human capital is not yet available, and researchers currently describe these in a variety of ways. For example, Currie and Stabile (2009), argue that non-cognitive aspects of human capital "are likely to capture some aspects of mental health as well as innate character traits" (for instance, being extroverted).
\end{abstract}

An important gap in this promising strand of literature is a full understanding of whether the deleterious effects of mental disorders on human capital are malleable when addressed through policy or clinical intervention. In the last several decades, innovations in pharmaceutical and behavioral treatments for mental health conditions have drastically altered the treatment of emotional and behavioral problems in children. This paper exploits a dramatic change in treatment of a common condition during adolescence -- depression -- to

\footnotetext{
* Susan H. Busch is an associate professor in the Department of Health Policy and Management at Yale University. Ezra Golberstein is an assistant professor in the Division of Health Policy and Management and the Minnesota Population Center at the University of Minnesota. Ellen Meara is an associate professor in the Dartmouth Institute for Health Policy and Clinical Practice and a Faculty Research Fellow at the National Bureau of Economic Research.

This research benefitted from the helpful comments and suggestions from Catherine Fullerton, Nora Gordon, Jon Skinner, Erzo Luttmer, Anthony LoSasso, several anonymous referees, and from seminar participants at Yale University, Harvard University, University of Minnesota, Dartmouth College, the University of Michigan, the University of Chicago, the NBER Health Care Meetings, the 2011 American Economic Association Meetings, and the 2012 Midwest Health Economics Conference. The data used in this article can be obtained beginning six months after publication through three years hence from Ezra Golberstein, Division of Health Policy and Management, University of Minnesota School of Public Health, 420 Delaware St. SE, MMC 729, Minneapolis, MN 55455; egolber@umn.edu.
} 
examine how the condition and its treatment affect a broad set of human capital measures including academic outcomes, delinquency, and substance use.

By age 18, an estimated 15 percent of US children will have experienced some type of depression (Merikangas et al. 2010). ${ }^{1}$ In adults, depression is associated lower rates of employment and lower earnings among individuals who do work (Ettner, Frank, and Kessler 1997). In adolescents, depression is associated with lower human capital investment. (Berndt et al. 2000; Ding et al. 2009; Fletcher, 2008). In addition to its effect on mood, depression causes restlessness, anxiety, difficulty with concentration, and feelings of worthlessness, all of which may inhibit academic performance or other aspects of human capital. However, depression's effect on human capital is difficult to measure due to omitted variable biases, described in more detail below. Hence, regulatory activities that altered the use of antidepressants offer a unique opportunity to learn about depression and its treatment.

In May of 2003, the manufacturer of Paxil, a popular antidepressant generically known as paroxetine, notified the Food and Drug Administration (FDA) that paroxetine increased suicidal thoughts and actions in some pediatric clinical trial participants. The FDA responded with a series of actions including public communications regarding the safety of paroxetine, public hearings regarding evidence on the safety of all antidepressants, and ultimately, the October 2004 decision to require black-box warnings regarding the safety of pediatric antidepressant use on virtually all antidepressant product labels and packaging.

The evidence to date, described below in detail, demonstrates that the FDA's release of this new safety information was widely covered in the popular press (Barry and Busch, 2010), and accompanied abrupt declines in pediatric and adolescent antidepressant use of 20-30 percent following years of steady increases in pediatric and adolescent antidepressant use (Busch et al. 2010; Gibbons et al. 2007; Libby et al. 2007; Nemeroff et al. 2007; Olfson, Marcus, and Druss 2008; Rosack, 2005). During the period immediately before and after the FDA warnings on antidepressants, the extensive margin of treatment (seeking any treatment versus none) did not change measurably, as we describe below. However, care along the intensive margin ( the total treatment delivered to those treated) fell as patients were less likely to receive antidepressants, and no evidence suggests any substantial replacement of antidepressant therapy with behavioral therapies like counseling. Throughout the paper, we refer to this movement along the intensive margin from treatments that include an antidepressant to those that do not as a decline in treatment. Critics of the FDA warnings expressed concerns regarding the impact of the warnings on clinical outcomes. These concerns increased when youth suicide rates climbed abruptly in 2004 and 2005, following a decade of relatively steady decline (Bridge et al. 2008; Gibbons et al. 2007).

To examine the effects of treated and untreated adolescent depression on human capital outcomes, we exploit the abrupt change in pediatric antidepressant use induced by FDA warnings to compare outcomes of adolescents who sought professional help for depression problems just before and just after the release of the FDA advisories in 2004. This unique

${ }^{1}$ In addition to mood and suicidal thoughts/actions, the Diagnostic and Statistical Manual of Mental Disorders-Fourth Edition's diagnosis of depression includes changes in: sleep, eating, energy, concentration, and self-image. 
natural experiment permits us to examine several questions with relevance for the economics of human capital, for health policy, and for clinical practice. First, it allows us to study potential unintended consequences of a regulatory policy designed to protect pediatric patients from safety risks of a widely used class of pharmaceuticals. Second, the FDA's actions permit us to estimate effects of reducing the pharmaceutical treatment of depression on human capital development in adolescents. Third, we compare the effects of depression problems among adolescents more and less likely to receive antidepressants, in a real world setting, rather than the more pristine setting of clinical trial research.

Using seven years of the annual cross-sectional National Survey on Drug Use and Health (2001-2007), we use a difference-in-difference design to study academic and behavioral outcomes in over 100,000 adolescents aged 12-17, comparing outcomes for adolescents with and without a recent episode of probable depression. Compared to other adolescents, adolescents with probable depression experienced a relative decline in grade point average (GPA) of .14 points after heightened FDA attention to the safety of antidepressants, and changes in average GPA for depressed adolescents were driven entirely by declines among adolescent girls. We find no change in average grades among adolescents without recent episodes of probable depression. We also find similar patterns for substance use and delinquency outcomes for adolescents with probable depression, relative to other adolescents. We do not find any evidence that our results are explained by compositional changes in the group of adolescents with probable depression.

The paper proceeds as follows: section I provides background on the FDA actions surrounding antidepressant use in pediatric patients and media coverage of FDA announcements, advisories and warnings; section II describes changes in prescribing patterns and youth suicides surrounding the 2003 and 2004 FDA actions; section III explains the data and methods in detail; section IV presents our regression analyses for academic outcomes, substance use, and delinquency; section $\mathrm{V}$ discusses potential threats to our approach; and section VI concludes.

\section{FDA Activity On The Safety Of Pediatric Antidepressant Use}

Antidepressant use among adolescents rose steadily and substantially throughout the 1990's and the early 2000's (Olfson, Marcus and Druss, 2008; Olfson et al. 2002). This increase likely stemmed from several sources. First, the development of Selective Serotonin Reuptake Inhibitors (SSRIs) shifted the balance between the risks and benefits of using antidepressants to treat patients with depression; earlier generation antidepressants were lethal in overdose. FDA approval of the SSRI Prozac (fluoxetine) for depression treatment in children further increased the willingness of clinicians, including general practitioners, to prescribe antidepressants to children. Of the antidepressants available to treat depression today, fluoxetine has the most evidence supporting its use. In 2004, a landmark multisite randomized trial of depressed adolescents treated with fluoxetine alone or fluoxetine with cognitive behavioral therapy showed significant improvements in depression symptoms compared with a placebo (Treatment for Adolescents With Depression Study Team 2004). Greater attention to mental health problems in youth, as evidenced by the 2003 Surgeon General's report, also may have resulted in increases in treatment. This was also a time when 
antidepressants were heavily marketed to health care professionals and directly to consumers (Rosenthal et al. 2002; Thomas et al. 2006). However, the growth of child and adolescent antidepressant use reversed abruptly with the disclosure of possible new safety risks, disseminated by the FDA in a series of public advisories and warnings.

Figure 1 shows the dates of major FDA activity and media coverage of the concerns regarding pediatric use of antidepressants. The FDA's five specific public communications on pediatric antidepressant use began in June 2003 with a one-page warning about potential risks of increased suicidal thoughts or actions for a single SSRI, Paxil (generically known as paroxetine). Subsequent risk communications increased the scope of the warnings. After considering evidence from hearings, and evidence presented in an FDA-sponsored metaanalysis of 24 randomized controlled trials, an FDA joint advisory committee voted to recommend a black box warning, although 8 of the 23 members dissented. ${ }^{2}$ A black box warning, or a required insert in the packaging of a prescription drug warning of serious or life threatening adverse side effects, is the strongest warning required by the FDA. In October 2004, the FDA issued a public health advisory directing drug manufacturers to include a black box warning of increased suicidality risk for children and adolescents on a broad range of antidepressants beginning January 1, 2005. These warnings strongly urged providers to increase monitoring of pediatric patients using antidepressants. As shown in Figure 1, media coverage of FDA activity was moderate in response to the June 2003 warning regarding Paxil, but it was heavier in March of 2004 in response to FDA public hearings and a broad advisory, as well as in the latter half of 2004 when the FDA announced its decision regarding black box warnings. Barry and Busch (2010) further document that media coverage was more negative in early 2004 , focusing on the possible safety risks of antidepressants, rather than potential benefits. Later in 2004, there was more attention given to the controversy regarding the FDA's decision to require black box warnings.

\section{Changes In Antidepressant Use And Youth Suicides}

In recent years, multiple studies have documented large declines in pediatric antidepressant use coincident with the 2004 FDA advisories and warnings, with most estimates suggesting that antidepressant use fell by 20 percent to 30 percent relative to the peak levels of antidepressant use in the 12 to 24 months surrounding the warnings (Busch et al. 2010; Busch et al. 2011; Gibbons et al. 2007; Kurian et al. 2007; Libby et al. 2007; Nemeroff et al. 2007; Olfson, Marcus and Druss 2008; Valluri et al. 2010). The most-often cited of these studies are summarized briefly in Appendix Table I. ${ }^{3}$

Studies that focus on monthly antidepressant sales demonstrate an initial abrupt decline in pediatric antidepressant prescriptions in January-March of 2004, the time of public hearings on the safety of pediatric antidepressant use (Kurian et al. 2007; Nemeroff et al. 2007). One study of all-payer data, representing about half of all prescription activity in the U.S., shows

\footnotetext{
${ }^{2}$ The FDA commissioned meta-analysis found a two fold increase in risk of suicidal thoughts and actions (suicidality) in youth taking antidepressants, compared to placebo groups (four versus two percent). This evidence has been criticized because it considered suicidality (suicide is a rare event and no child in any of the trials considered committed suicide) and many trials excluded youth who were suicidal at baseline.

${ }^{3}$ The appendix tables can be found at http://jhr.uwpress.org/.
} 
the precipitous drop in the number of prescriptions for children under age 18 that occurred in January-June 2004, coincident with intense media coverage of FDA's hearings and its second advisory on safety risks of pediatric antidepressant use (Nemeroff et al. 2007).

Based on clinical trial evidence, one may view treatments for pediatric depression on a continuum regarding their efficacy. Combination treatment, or antidepressants in conjunction with evidence-based psychotherapy, reduced symptoms of depression most in randomized clinical trials, followed by antidepressants alone, and then evidence-based psychotherapy alone (Treatment for Adolescents With Depression Study Team 2004). ${ }^{4}$ In effect, the FDA warnings moved adolescents along this continuum toward less effective treatments. This is particularly true given that most patients receiving "psychotherapy alone" in real-world clinical settings receive far fewer psychotherapy visits and lower quality therapy than what was received by trial participants (Busch et al. 2006; Olfson et al. 2002). Some children who previously would have received combination treatment received psychotherapy alone. Others moved from antidepressant treatment alone to no evidencebased treatment. The literature is mixed on whether or not the receipt of psychotherapy increased after the warnings. One study suggests there was a slight increase in receipt of any psychotherapy - among treated adolescents, the percent receiving at least one psychotherapy visit rose less than 5 percent in the period after the warnings (Valluri et al. 2010). In contrast, other studies found no such increase (Busch et al. 2010; Libby et al. 2007). In addition, the types of providers prescribing antidepressants shifted, with primary care physicians writing a smaller share of total antidepressant prescriptions compared with psychiatrists after the FDA warnings (Nemeroff et al. 2007; Olfson, Marcus and Druss 2008).

Because our study design relies on the timing of the abrupt shift in antidepressant use among adolescent patients with depression, we present additional evidence on antidepressant patterns for 12-17 year olds from two complementary sources, Florida Medicaid claims data and Marketscan data, a large administrative database of pharmaceutical claims for privately insured individuals. The Marketscan data include all individuals with diagnoses of depression in a given quarter based on International Classification of Diseases, Ninth Revision (ICD-9) Codes 296.2, 296.3, 300.4, and 311. Antidepressant use is defined as one or more claims for any of 36 antidepressants covered by the FDA black box warning in that quarter. In the Florida Medicaid data, these include only pediatric patients with new diagnoses of depression using the same codes above. We defined new diagnoses of depression as those without any code for depression in the 120 days prior to an initial diagnosis of depression. In the Florida data, antidepressant use is defined as one or more claims for any of 36 antidepressants covered by the FDA black box warning within 30 days of diagnosed depression. ${ }^{5}$ Figure 2 plots the antidepressant prescription fills from both of these data sets. Despite slightly different definitions and time periods, the prescribing

\footnotetext{
${ }^{4}$ This widely cited multisite randomized trial found combination treatment to be superior to fluoxetine alone or cognitive behavioral therapy alone. Rates of response (i.e. a significant decline in depression symptoms) for the four treatments studied were Combination, or fluoxetine with cognitive behavioral therapy ( 71 percent) fluoxetine alone (62 percent), cognitive behavioral therapy alone (43 percent), and placebo (35 percent). This study provided 15 psychotherapy visits in 12 weeks to children in the therapy arms of the trial.

${ }^{5}$ We also examined trends in use of antidepressants within 60 days or 90 days of diagnosed depression. Although the levels are higher in the 60-day and 90-day windows, the trends in antidepressant use are very similar.
} 
patterns are remarkably similar in the Marketscan and Florida Medicaid data. Prescriptions fall abruptly beginning in the first quarter of 2004 (although girls in the Marketscan data show a drop starting one quarter earlier). Also of note, the prescribing patterns are similar across sexes. Comparing 2003 to 2005, the relative declines were smaller in the Marketscan data (about 10 to 15 percent relative decline) compared with the Medicaid data (about 25 to 30 percent relative decline). The greater drop in a sample made up exclusively of pediatric depression patients with new episodes of depression is consistent with the notion that changes in prescribing in response to FDA advisories and warnings affected new depression episodes more than existing episodes (Busch et al. 2011).

Figure 2 depicts the timing of drops in antidepressant use in two populations, but it is important to understand how the FDA activity on antidepressants affected prescribing patterns in a broader national population. Using adolescents aged 12 to 17 in the nationally representative Medical Expenditure Panel Surveys (2002-2006), we estimate the proportion with any antidepressant use in a calendar year among those with one or more medical encounters for depression. The MEPS sample is considerably smaller than the samples depicted in Figure 2, and the diagnoses are a little less precise than those in actual claims data. ${ }^{6}$ In addition, data are not available by quarter. Nonetheless, Figure 3 shows a dramatic absolute decline of over 20 percentage points ( 24 for boys and 22 for girls) in antidepressant use between 2003 and 2005, or a relative decline of over 30 percent. We note that this graph suggests little decline in 2004; this is likely due to the use of calendar year prevalence - data from 2004 include months where rates of antidepressant use were still increasing.

To establish a link between declines in antidepressant use and human capital among depressed adolescents, one also needs to examine whether symptoms of depression changed after changes in treatment (reductions in antidepressant use). Earlier we noted the clinical trial evidence of the efficacy of treatment in reducing depression symptoms in adolescents. To better understand how the FDA activity around pediatric antidepressant use may have affected symptoms in the population of adolescents with depression, we present information regarding suicides in the United States over the period from 1999 to 2007 (Figure 4). Suicide represents the most extreme consequence of depression, and one that depression treatments target. The data in Figure 4 are drawn from the Centers for Disease Control and Prevention's publicly available information on deaths by cause and selected demographic characteristics. Because of dramatically different levels of suicides by age and gender (males commit suicide more often, and between ages 10 and 24, suicide rates rise with age), we present the natural log of suicide deaths per 100,000 population, separately for two age groups (10-19 and 20-24), and by sex. Because the 2004 FDA warnings applied to pediatric antidepressant use, they did not directly affect 20-24 year olds. Youth suicides had been flat or declining among 10-19 year olds in the years preceding the warnings, but in 2004, 10-19 year old girls experienced a sharp increase in suicides, of over 30 percent. There was no abrupt rise among older ages (20-24) as expected, given that these early warnings focused

\footnotetext{
${ }^{6}$ The MEPS reports 3-character International Classification of Disease-9th Revision codes. We defined a cohort of depressed children using code 296 (affective psychoses), 300 (neurotic disorders), and 311 (depression Not Elsewhere Classified). This category is necessarily broader than that defined in administrative data from Florida Medicaid, for example, but more specific than what is available in the NSDUH based on seeking treatment.
} 
on pediatric populations. These results echo those presented by Gibbons and colleagues (2007), but include three additional years of data (through 2007). Gibbons and colleagues also note that since 1988, U.S. youth suicide rates have declined in all but two years (1994 and 2000), and these increases were much smaller than the increase in suicides in 2004. Taken together, we interpret the trends in antidepressant use and the concomitant rise in youth suicide as evidence that symptoms of depression rose in the adolescent population in 2004 and 2005 in response to the FDA advisories and warnings on the safety of pediatric antidepressant use. We use this abrupt change in treatment and symptoms of depression to identify human capital effects of depression treatment.

\section{Empirical Methods And Data}

\section{A. Contribution to the Literature and Overview of Identification Strategy}

Researchers have attempted to quantify the impact of depression on human capital by examining measures of academic achievement, but even the most rigorous evidence to date makes causal inference regarding the effect of depression difficult. More importantly, there is no evidence from real world settings (as opposed to randomized clinical trials) that treating adolescent depression can improve academic outcomes. Fletcher (2008) estimates the relationship between adolescent depression status and educational attainment, identifying the effect of depression using fixed effect models, which effectively compare adolescent siblings with and without symptoms of depression. His analysis documents a correlation between depression and poorer educational attainment for girls, but not for boys. The interpretation of this analysis relies on the assumption that only differences in depression cause the observed differences in academic outcomes, rather than some fixed trait like motivation or ability that might be correlated with depression, yet differs across siblings.

Another study uses genetic markers as identifying instruments for adolescent depression and finds a significant negative effect of depression on grade point average, but again these significant effects are only observed for girls (Ding et al. 2009). This approach requires the assumption that the genetic marker relates only to depression, and not other unmeasured traits that could influence grade point averages. Other research using person-level fixed effects models for a sample of a somewhat older age group (college students) does not find gender differences in the relationship between depression and grade point average (Eisenberg, Golberstein, and Hunt 2009). These three studies mark significant progress toward the goal of understanding human capital effects of depression during the crucial period of adolescence, but each relies on relatively strong, and somewhat similar assumptions that depression, and not related unmeasured traits, drives academic differences within families, according to genetic markers, or within an individual over time. None of these studies provides information regarding the treatment of depression and academic achievement.

Researchers have also attempted to quantify the effect of adolescent depression on other outcomes that represent non-cognitive dimensions of human capital including substance use and delinquency, but similar to the case of academic achievement, identifying causal effects is difficult. For example, recent literature showed that state-level rates of antidepressant use 
are correlated with violent crime rates, but not with property crime rates (Marcotte and Markowitz 2010). When these researchers focusing specifically on prescription rates and crime rates for teenagers, they find little evidence that psychiatric drugs, and antidepressants in particular, are associated with either homicide rates or arrest rates for violent and property crimes. A 10-year longitudinal follow-up of the National Comorbidity Survey confirmed that individuals with major depression at baseline (1990-92) were much more likely to initiate the use of illicit drugs in the subsequent decade compared to individuals without major depression (Swendsen et al. 2010). Adolescents aged 12-17 with a major depressive episode in the past year were twice as likely to initiate illicit drug use compared with those without depression (16.1 versus 6.9 percent) (SAMHSA 2007).

Despite ample research on depression and substance use, causal evidence on the effect of depression treatment on these outcomes is rare. Epidemiologic studies that present correlations between depression and substance use disorders cannot distinguish a causal role for depression from a case in which substance use disorders cause depression or a case in which a third factor contributes to both depression and substance use disorders (Breslau et al. 1998; Glantz 2002; Jane-Llopis and Matytsina 2006; Swendsen et al. 2010).

Experimental studies on the effects of depression treatment target a narrow range of pediatric patients (excluding, for example, patients with a history of substance abuse), and focus on a limited set of clinical outcomes.

To augment existing literature on adolescent depression and academic and related human capital outcomes with a complementary and stronger identification strategy, and to answer the clinical and policy relevant question of whether treating depression can improve human capital outcomes, we take advantage of a powerful natural experiment: the sudden decline in use of antidepressants for treating pediatric depression induced by the FDA's 2003-2004 warnings on the risks of suicidality associated with pediatric antidepressant use. We compare academic and behavioral outcomes for adolescents who sought treatment for depression just before and just after the sharp drop in adolescent antidepressant use in the first quarter of 2004. Adolescents without recent episodes of depression serve as a comparison group. Our identification relies on the assumption that any difference in prescribing patterns and outcomes immediately before versus immediately after the first quarter of 2004 relate only to FDA hearings and advisories, and thus mimics random variation.

\section{B. National Survey on Drug Use and Health}

The data for our analyses come from the National Surveys on Drug Use and Health (NSDUH). ${ }^{7}$ The NSDUH is an annual survey conducted by the Substance Abuse and Mental Health Services Administration that collects data from approximately 70,000 individuals aged 12 and older who are representative of the U.S. population. Several features of the NSDUH are particularly salient for our analyses. The NSDUH is in the field yearround and the public-use version of the dataset includes a variable indicating the quarter in which the interview occurred. The NSDUH has a large sample of adolescents, as 12-17 year

\footnotetext{
${ }^{7}$ Prior to 2002, the survey was called the National Household Survey on Drug Abuse.
} 
olds comprise approximately one third of the total samples. In addition, although the NSDUH focuses on substance use issues, it also collects survey data on mental health, education, and delinquency. In our main analyses, we use the 2001-2007 years of the NSDUH. After restricting to adolescents, that yields a sample size of 126,355 observations during all 28 quarters from 2001-2007. Our analyses have slightly smaller samples of adolescents for two reasons. All analyses exclude the first quarter of 2004, due to the fact that it straddles months that can be thought of as pre- or post- period. This exclusion, combined with missing information on academic outcomes leaves 106,635 $(121,785)$ observations in models of academic (substance use) outcomes. ${ }^{8}$ Finally, outcome variables related to stealing and fights cover the 12 month period before the survey, so we exclude the first two quarters of 2004 to have a cleaner pre- and post- period, leaving 116,371 observations with complete information on delinquent behaviors.

\section{Depression Measure}

As described above, our key comparison is in academic outcomes for adolescents with probable depression before and after the FDA warnings about antidepressant risks. A more ideal measure of depression status based on a validated diagnostic instrument was not asked of adolescents in the NSDUH until 2004. Instead, we proxy for probable depression status by using information collected from adolescents about whether they received any treatment or counseling services for emotional or behavioral problems from a diverse set of sources over the past 12 months. This population reflects those we most expect to be affected by the warning. The NSDUH asks respondents whether they stayed overnight in a hospital, in a residential treatment center, or in therapeutic foster care. Respondents also report whether they received any services for emotional or behavioral problems from a partial day hospital or day treatment program; from a mental health clinic or center; from a private therapist, psychologist, psychiatrist, social worker, or counselor; from an in-home therapist, counselor, or family preservation worker; from a pediatrician or other family doctor; whether they talked to school counselors, school psychologists, or had regular meetings with teachers about emotional or behavioral problems.

For each of the services that a respondent reported using in the past 12 months, the respondent is asked a series of closed-ended questions to determine why they used that service. Two of those follow-up questions are used to identify probable depression: Whether the services were because the respondent thought about or tried to kill themselves, or because the respondent felt depressed. ${ }^{9}$ All of the questions related to mental health treatment were asked in a consistent manner in the 2001-2007 surveys. We code someone as having probable depression if they respond that they used any of the above services (excluding services from school counselors, psychologists, and teachers since they would

\footnotetext{
${ }^{8}$ We explored the large number of missing observations for academic outcomes. About 2.5 percent of respondents have missing grade point information because their schools do not report letter grades and another six percent report that they did not attend school in the past year. One might expect drop out rates to increase if adolescents receive less treatment of depression following changes in prescribing patterns. This would bias us against finding adverse effects on school outcomes. We confirmed that the probability respondents report attending school at the time of the survey did not fall coincident with the change in prescribing patterns that occurred with the FDA activity in 2004. There is no change in the trend in school attendance over the time period we study.

${ }^{9}$ The other possible explanations were because the respondent felt afraid or tense, because of breaking rules or acting out, because of eating problems, or because of some other reason.
} 
not be prescribers of antidepressants) and if that service was used because of suicidality or depression. ${ }^{10}, 11$ As shown in Table 1, 6.6 percent of the sample is classified as having probable depression. This definition of probable depression excludes individuals who might use antidepressant medication but would not report using mental health services for depression (perhaps because they were taking antidepressants for other conditions such as anxiety). This would likely bias our results toward the null. ${ }^{12}$

Table 1 shows sample characteristics separately by gender and whether an adolescent was depressed, according to the definition above. As expected, probable depression is more common among females ( 8.5 percent depressed) than males ( 4.8 percent depressed). Compared with non-depressed adolescents, the depressed respondents are slightly older, more likely to be white, and more likely to live in families with moderate or low-income levels.

\section{Outcome Measures}

We examine three types of outcomes: academic achievement, substance use, and delinquency. We measure academic achievement using the respondents' self report of their average grades in the most recent grading period. In the NSDUH, respondents select one of four choices: A+/A/A-, B+/B/B-, C+/C/C-, or D or lower. When treated as a cardinal measure, this variable has an interpretation that is similar to GPA, with 4.0 indicating the highest grades. ${ }^{13}$ We also evaluated a set of intermediate schooling measures regarding school attendance and adolescent attitudes toward school, but these results were imprecisely estimated, and for brevity, we omit them here.

Next we examine outcomes relating to substance use in the past 30 days. Respondents were asked, "In the last 30 days on how many days did you..." have 5 or more drinks on the same occasion?; smoke part or all of a cigarette?; use (an illicit drug or in the case of prescription drugs, use___non-medically)? ${ }^{14}$ We used these questions to form indicator variables for binge drinking, cigarette use, illicit drug use, and nonmedical prescription drug use in the past 30 days. Finally, we examined measures of delinquency. Respondents were asked, "During the past 12 months, how many times have you... stolen or tried to steal anything worth more than $\$ 50$ ?; gotten into a serious fight at school or work? Attacked someone with the intent to seriously hurt them?" We used these responses to create indicator variables regarding fighting, stealing, and attacking.

All of our outcome measures are summarized in Table 2. Our sample characteristics match the literature on academic outcomes. Grades are slightly higher on average for females than

\footnotetext{
${ }^{10}$ For brevity, throughout the paper, we refer to those classified as having probable depression as "depressed".

${ }^{11}$ While the size of the group with probable depression grows moderately if we include the school-based services in our definition, our substantive results are unchanged.

12 The 2004-2007 NSDUH data show that our measure of probable depression does correlate reasonably well with the NSDUH's clinically-validated measure of major depression. Against this standard, our measure produces very few (4.7 percent) false-positive assignments of probable depression.

${ }_{13}$ We also estimate ordered probit models for this outcome, but our results are unchanged.

${ }^{14}$ Respondents were prompted individually about an exhaustive list of drugs in the following categories (marijuana, heroin, cocaine, crack, LSD, PCP, ecstacy, methamphetamine, hallucinogens, inhalants, sedatives, stimulants, tranquilizers, pain relivers, and oxycontin), and the NSDUH recodes responses to reflect any positive response to an illicit drug, or any response that indicates inappropriate prescription drug use).
} 
males, and depressed adolescents fare slightly worse than their non-depressed peers. Our delinquency measures suggest that a significant minority of children engaged in fighting and stealing. About 42 percent of boys and 34 percent of girls with a recent episode of depression reported one or more fights in the past 12 months, compared with 25 percent of boys and 17 percent of girls in the non-depressed group. Stealing and "attacking" with the intent to hurt someone were less common. Less than 10 percent of non-depressed kids reported this behavior, while 23 percent of boys and 15 percent of girls in the depressed group had attacked someone in the prior 12 months.

Substance use was not uncommon, especially among the depressed adolescents. In this group, 16(19) percent of boys(girls) reported binge drinking, 21(26) percent of boys(girls) reported using cigarettes, 22(21) percent of boys(girls) had used an illicit drug, and 8(9) percent of boys(girls) had used prescription drugs inappropriately in the prior 30 days. In all cases but binge drinking, substance use was twice as common in the depressed adolescents compared with their non-depressed peers.

\section{E. Empirical models}

Our basic regression specification employs the model described in Equation (1).

$$
\begin{aligned}
Y_{i t}= & \alpha+\beta_{1} \text { Time }_{t} \\
& +\beta_{2} \text { PostFD }_{t} \\
& +\beta_{3}(\text { PostFDA*Time })_{t} \\
& +\beta_{4} D_{i t}+\beta_{5}(D * \text { Time })_{i t} \\
& +\beta_{6}(D * \text { PostFDA*Time })_{i t} \\
& +\delta X_{i t}+Q_{t}+\varepsilon_{i t}
\end{aligned}
$$

$Y$ denotes any one of our outcome variables. Our time variable $t$, is a linear time trend over the 28 quarters of our study period. The variable PostFDA has a value of zero until the first quarter of 2004 and a value of one after that. The variable $D$ indicates whether a respondent falls into the depressed group. We allow the time trend to vary by PostFDA and by depression status. ${ }^{15}$ The vector $X$ includes a set of sociodemographic variables. These variables include a dummy variable for sex, a linear age trend, and a set of dummy variables for race/ethnicity (white, black, native American, native Hawaiian/Pacific islander, Asian, more than one race, or Hispanic). $X$ also includes a set of dummy variables for family income $(<\$ 10,000, \$ 10-29,999, \$ 20-29,999, \$ 30-39,999, \$ 40-49,999, \$ 50-74,999, \$ 75,000$ or more). $Q$ represents a set of quarter dummies to adjust for seasonality. In these models, the key coefficient that identifies the effect of the FDA warnings on human capital outcomes for adolescents with probable depression after controlling for underlying trends in academic achievement is $\beta_{6}$.

We estimate our main models of academic achievement using OLS. For our other outcome variables, which are dichotomous, we estimate probit models. In the tables, we present probit coefficients, and for our main variables of interest, we provide the marginal effects as

\footnotetext{
15 Adding a quadratic term or higher-order polynomials to the time trends did not affect our main coefficients of interest.
} 
well as bootstrapped standard errors of the marginal effects (based on 500 replications of samples drawn with replacement). All of our regression models utilize the NSDUH sampling weights to be representative of the U.S. population. We estimate our models with heteroskedasticity-robust standard errors clustered on the time period (defined by quarter of measurement).

\section{Results}

We first present graphical evidence of the trends in academic achievement for adolescents with probable depression. Figure 5 shows the average grades for adolescents with probable depression, where each point indicates average grades in a quarter. In the periods before the FDA warnings, there are no discernable trends in average grades for adolescents with and without probable depression. After the FDA warnings, the average grades dropped abruptly for depressed girls, though not for depressed boys. In addition, Figure 5 also shows the trend in average grades for adolescents without probable depression. As expected, the average grades for adolescents without probable depression are higher than those for depressed adolescents. Average grades for adolescents without depression were flat throughout the study period, with no apparent change around the time of the 2004 FDA advisories and warnings.

Table 3 shows the results of the regression models of our main outcome variable, average grades. The results for column 1 are for the full sample. The key coefficient of interest, $\beta_{6}$, is estimated to be -0.142 , implying that average grades dropped significantly after the FDA warnings. The regression results also confirm the graphical evidence. The key coefficient for females (column 2$)$ is larger in magnitude $\left(\beta_{6}=-0.203\right)$ and more precise than the coefficient for males, which is not significantly different from zero $\left(\beta_{6}=-0.030\right)$. Table 4 examines whether these effects occurred throughout the grade distribution by estimating models of whether respondents report having an A average or better, a B average or better, or a $\mathrm{C}$ average or better. Adolescents with a recent episode of probable depression were 8.6 percentage points less likely to earn a B or better and 3.5 percentage points less likely to earn a $\mathrm{C}$ or better after the FDA advisories in early 2004. This was driven by the depressed girls, who were 11 percentage points less likely to earn a B or better and 6 percentage points less likely to earn a $\mathrm{C}$ or better following the FDA advisories. There appears to be little effect of FDA advisories and the decline in depression treatment on the likelihood of reporting an A average.

Table 5 shows key coefficients and marginal effects of the FDA warnings on substance use. Smoking increased in the full sample by 4.6 percentage points. Although depressed adolescents are much more likely to binge drink than their peers, the FDA advisories appear to have little effect on binge drinking. Among girls, the FDA advisories and decline in the treatment of depression increased the use of illicit drugs by 5.4 percentage points and increased nonmedical prescription drug use by 4.3 percentage points. As with academic outcomes, the effects on illegal drug use and nonmedical prescription drug use are driven mainly by girls rather than boys, although the effects on cigarette use are similar across gender. 
Table 6 shows key coefficients and marginal effects of the FDA warnings on delinquency outcomes. Fighting and stealing both rose disproportionately among depressed adolescents in the post period. Fighting rose by 6.5 percentage points and stealing rose by 4.6 percentage points in the full sample, although the effects on stealing were driven entirely by depressed girls. There was no significant effect of the FDA warnings on attacks in the last 12 months. Taken together, our results suggest there were important adverse consequences of the FDA advisories on grades, substance use, and other delinquent behavior. Depressed girls seem to have been affected most by these unintended consequences, since we measured no significant changes in grades or behavior among boys with likely depression. Next we consider several alternative interpretations of our findings.

\section{Alternative Interpretation Of The Results}

In this section, we address several potential threats to our interpretation of the results. The most obvious concern is that with so much change in the treatment of depression, the composition of the "depressed" group is changing in ways that could bias us towards the conclusion that the FDA warnings had an adverse impact on depressed adolescents. If, for example, the marginal depression patient, in terms of severity, was less likely to seek treatment following the FDA warnings, we would worry that the remaining set of depression patients might be sicker and have worse human capital outcomes than those patients who opted not to seek treatment. To explore this concern, we examined both the trend in and the composition of our sample of adolescents with probable depression. Figure 6 plots the share of adolescents with probable depression throughout our study period, and we report the results of tests for significant changes in the level or trend of depressed adolescents in the post-period of our analysis. The plotted raw data do not show any abrupt changes in the share of adolescents who report seeking treatment for depression. In the regression models of depression status as a function of time, there was no decline in the share of adolescents aged 12 to 17 seeking treatment for depression after the FDA warnings. ${ }^{16}, 17$

In Table 7, we estimated models like those in equation 1, using each of the covariates included in $X$ as our outcome variable (controlling only for quarter of survey). We tested whether the coefficient on Depress*Post-FDA was significant, indicating that characteristics of adolescents in the depressed group changed substantially with the change in prescribing patterns. Table 7 shows that there were no consistent or meaningful changes in race, ethnicity, gender, income or age of adolescents seeking treatment for depression. Out of 40 coefficients, only two were significant at $\mathrm{p}=0.05$. This suggests that our estimated effects of the FDA warnings are not explained by compositional changes in who is depressed. ${ }^{18}$

\footnotetext{
${ }^{16}$ Data from the nationally representative MEPS (not shown) corroborate the NSDUH trends. There are no statistically significant differences in annual rates of depression treatment among 12-17 year olds for any of the years between 2002 and 2006.

${ }^{17}$ As described in Figure 6, the coefficient on the PostFDA dummy suggests a small increase in the share of adolescent males with depression, which is marginally significant at $\mathrm{p}=.058$. For females, there is no evidence of a change in the share of adolescents with depression in the post-period.

18 As a rough check of the extent of compositional change needed to affect our results, we calculate what the pre-post change in depression would be for depressed girls if 10 percent of the depressed girls in the pre-period were switched into the non-depressed group and assume that the 10 percent had been the highest achieving. Even in that rather extreme scenario, the GPA difference between depressed and non-depressed girls does not grow enough to explain our main results.
} 
We also investigate whether there is evidence that the adolescents in the depressed group appear "more depressed" in the post-period, a finding one would expect if the decline in antidepressant use occurred among marginal patients who were less severely depressed, and less likely to benefit from antidepressants. To the extent that the depressed group was comprised of adolescents with more serious depression, this could generate our observed trends even if antidepressants had no effect on depression or human capital outcomes. To assess this possibility, we look at the types of depression services that were used by the depressed adolescents. We do not find any evidence of changes in the more-serious forms of depression treatment (inpatient care and residential care), suggesting that compositional change in terms of depression severity is unlikely to explain our results (results available upon request).

A second factor to consider during this time period is whether we might be measuring a broader concern about all psychotropic medication. Several studies have examined whether there were changes in use of antipsychotics or other psychotropic drugs (for instance, stimulants or benzodiazapines) (Libby et al. 2007; Nemeroff et al. 2007). None of these studies found changes in use of other psychotropic medications. We examined this possibility by computing the annual prevalence rate of stimulants in the MEPS and found no changes in use.

Finally, one may question how reasonable it is to find effects for girls but not for boys. We turn to this next. One reason we might observe such a result could be that antidepressants are less effective to treat depression in males versus females. The clinical literature has evaluated the effects of various antidepressants by gender with mixed results. For example, a recent review of studies on sex differences in effects of antidepressants summarizes evidence both supporting and refuting differential efficacy of antidepressants by sex (Marsh and Deligiannidis 2010). However, studies focused on SSRIs in larger patient populations, such as a study of citalopram in the Sequenced Treatment Alternatives to Relieve Depression, or STAR*D trial, document significantly larger treatment effects among women relative to men (Young et al. 2009). Furthermore, differential effects of antidepressants by gender have been concentrated among patients under age 50, leading some to hypothesize that hormonal activity affects the efficacy of antidepressants (Thase et al. 2005). These differences are too small to explain the dramatic effects for girls versus boys, though. Our results are consistent with other observational studies comparing the outcomes of depressed adolescents to non-depressed adolescents. Papers by Fletcher and Ding and colleagues (Ding et al. 2009; Fletcher 2008), as well as earlier work (Berndt et al. 2000) found that high school graduation rates and grades were lower for girls with depression compared to girls without, but they did not find similar results for boys. One piece of evidence that supports the notion that the FDA warnings were more important for girls than for boys is the evidence on suicides. The relative rise was large for girls, about 33 percent, and trivial among boys. This relationship merits further study.

\section{A. Magnitude of Response to Antidepressants}

Our analysis offers a reduced form estimate of the overall effect of the FDA advisories and warnings on human capital for adolescents with recent episodes of depression. However, an 
important back of the envelope calculation to better understand the clinical and policy implications of our results is to convert our estimates into an estimated effect of antidepressants on human capital outcomes among adolescents seeking care for depression. This computation requires an estimate of the absolute decline in antidepressant use for a population like that in the NSDUH data. The MEPS data presented in Figure 3 most closely mirror the NSDUH sample, although one should note that the diagnoses used to define the MEPS sample are slightly different than those used to characterize probable depression in the NSDUH. However, the absolute decline in antidepressant use of 22 to 24 percentage points, or about one fifth in the MEPS data suggest that when multiplied by a factor of five, our estimated effects of changes in outcomes in response to the FDA induced decline in antidepressant use yield a crude estimate of the magnitude of the effect of antidepressants on grades, substance use, and delinquency, among adolescents aged 12 to 17 with probable depression.

In other words, among depressed girls, where the effects are concentrated, treatment with antidepressants increases grades by a full point (from a $\mathrm{C}$ to a $\mathrm{B}$, for example), reduces the chance of smoking and illicit drug use by 20 to 25 percentage points, and reduces the chance of stealing or fighting by even greater magnitudes (about 30 to 35 percentage points). These suggest both large effects of untreated or undertreated depression, as well as an impressive treatment effect of antidepressants in the community during the period leading up to advisories and warnings regarding antidepressants. However, one should use caution when interpreting the magnitude of results as the impact of taking an antidepressant versus no antidepressant. Among pediatric patients receiving an antidepressant within 30 days of a new diagnosis, Busch et al. (2010) documented a significant decline in use of Paroxetine (20 percent to 5 percent from late 2003 through 2005) and a rise in Fluoxetine (13 percent to 28 percent over the same period). Furthermore, it is unclear whether the dosage of antidepressants may have changed in response. Thus, scaling our estimates by changes in the percent of adolescents treated with antidepressants may over-state the impact of antidepressants, since our reduced form approach captures the total change in outcomes for all depressed kids, including those with changes in the type or intensity of antidepressant use.

\section{Conclusion}

Few topics engender as much concern and controversy as treating children and adolescents with psychotropic drugs and academic achievement in the middle and high school years. Following the FDA's 2004 decision to issue black box warnings on virtually all antidepressants based on safety concerns in children and adolescents, both of these changed. Prior evidence documents a decline in antidepressant use of 20 to 30 percent following the FDA warnings. We find that academic achievement among depressed adolescent girls declined after the FDA warnings, falling roughly from a B to B-grade point average. This decline in grade point average did not occur among adolescents without a recent episode of probable depression. Academic outcomes were just one aspect of human capital affected by the warnings. Substance use and other delinquency measures increased among girls seeking treatment for depression as well. As noted in Section II, the decline in antidepressant use was driven by new episodes of depression. Hence, our results should be interpreted as 
effects of antidepressant use on human capital outcomes for adolescents with recent-onset depression.

These findings have several implications. They suggest that the unintended consequences of policies designed to protect consumer safety extend well beyond the clinical considerations that typically contribute to decisions about the costs and benefits of regulatory actions. The FDA's decision to issue the warning on antidepressants rested on evidence of suicidal thoughts and actions, but not suicide itself. Indeed, the FDA panel of experts convened to make the decision about a black box warning was divided regarding the relative costs and benefits of issuing the warning for public health. The "costs" of issuing the warning considered were clinical in nature, with potential suicide among depressed patients being the most extreme of these. However, the discussion did not consider the broader non-clinical costs (and benefits) of treating depression with antidepressants. More broadly, FDA decisions around pharmaceuticals exclusively consider clinical risks and benefits. Our evidence suggests that the FDA calculus does not account for potentially significant nonclinical benefits of treatment that may be highly-valued by consumers. The inclusion of such considerations could, in some cases, substantially affect the estimated net benefits of pharmaceuticals. Second, our findings also confirm research in very different settings suggesting that depression interferes with academic outcomes, especially for girls.

The third and most significant innovation of this empirical work is that it suggests that treatment of depression can mitigate adverse effects of depression on both cognitive and non-cognitive aspects of human capital among adolescents. Families, schools, and clinicians devote significant effort to help students with behavioral health issues because they interfere with academic outcomes. These findings suggest that treatment of depression can improve both cognitive outcomes such as grades, as well as delinquent behaviors and the initiation of substance use, all of which are important aspects of human capital.

Our paper focuses on outcomes that occurred within one to 12 months of being surveyed, and thus they should be viewed as relatively short-run outcomes. Given controversy over the risks and benefits of antidepressants in the long run, our findings do not suggest we should abandon other forms of treating depression, but rather as evidence that depression affects economic outcomes, and thus successful treatments of depression yields potential benefits that reach far beyond the clinical outcomes typically measured.

\section{Supplementary Material}

Refer to Web version on PubMed Central for supplementary material.

\section{Acknowledgments}

This work was supported by funding from the National Institutes of Health (grants R01 MH 080883, K01 DA019485, R01 DA030391, and 5T32 MH0119733) and the Harvard Center for the Developing Child

\section{References}

Barry, Colleen L.; Busch, Susan H. News Coverage of FDA Warnings on Pediatric Antidepressant Use and Suicidality. Pediatrics. 2010; 125(1):88-95. [PubMed: 19969614] 
Berndt, Ernst R.; Koran, Lorrin M.; Finkelstein, Stan N.; Gelenberg, Alan J.; Kornstein, Susan G.; Miller, Ivan M.; Thase, Michael E.; Trapp, George A.; Keller, Martin B. Lost Human Capital from Early-Onset Chronic Depression. American Journal of Psychiatry. 2000; 157(6):940-47. [PubMed: 10831474]

Blanden, Jo; Gregg, Paul; Macmillan, Lindsey. Accounting for Intergenerational Income Persistence: Non-Cognitive Skills, Ability and Education. The Economic Journal. 2006; 117(519):C43-C60.

Borghans, Lex; Duckworth, Angela; Heckman, James J.; Weel, Bas ter. The Economics and Psychology of Personality Traits. Journal of Human Resources. 2008; 43(4):972-1059.

Bowles, Samuel; Gintis, Herbert; Osborne, Melissa. The Determinants of Individual Earnings: Skills, Preferences and Schooling. Journal of Economic Literature. 2001; 39(4):1137-76.

Breslau, Naomi; Peterson, Edward L.; Schultz, Lonni R.; Chilcoat, Howard D.; Andreski, Patricia. Major Depression and Stages of Smoking. A Longitudinal Investigation. Archives of General Psychiatry. 1998; 55(2):161-66. [PubMed: 9477930]

Bridge, Jeffrey A.; Greenhouse, Joel B.; Weldon, Arielle H.; Campo, John V.; Kelleher, Kelly J. Suicide Trends among Youths Aged 10 to 19 Years in the United States, 1996-2005. Journal of the American Medical Association. 2008; 300(9):1025-26. [PubMed: 18768413]

Busch, Alisa B.; Huskamp, Haiden A.; Normand, Sharon-Lise; Young, Alexander S.; Goldman, Howard; Frank, Richard G. The Impact of Parity on Major Depression Treatment Quality in the Federal Employees' Health Benefits Program after Parity Implementation. Medical Care. 2006; 44(6):506-12. [PubMed: 16707998]

Busch, Susan H.; Frank, Richard G.; Leslie, Douglas L.; Martin, Andres; Rosenheck, Robert A.; Martin, Erika G.; Barry, Colleen L. Antidepressants and Suicide Risk: How Did Specific Information in FDA Safety Warnings Affect Treatment Patterns? Psychiatric Services. 2010; 61(1): 11-16. [PubMed: 20044412]

Busch, Susan H.; Frank, Richard G.; Martin, Andres; Barry, Colleen L. Characterizing Declines in Pediatric Antidepressant Use after New Risk Disclosures. Medical Care Research and Review. 2011; 68(1):96-111. [PubMed: 20675349]

Centers for Disease Control and Prevention, National Center for Health Statistics. Compressed Mortality File (CMF) on CDC WONDER Online Database. 2010. Available at http:// wonder.cdc.gov/cmf-icd10.html (accessed March 21, 2011)

Currie, Janet; Stabile, Mark. Mental Health in Childhood and Human Capital. In: Gruber, Jonathan, editor. The Problems of Disadvantaged Youth: An Economic Perspective. University of Chicago Press; Chicago: 2009. p. 115-48.

Ding, Weili; Lehrer, Steven F.; Neils Rosenquist, J.; Audrain-McGovern, Janet. The Impact of Poor Health on Academic Performance: New Evidence Using Genetic Markers. Journal of Health Economics. 2009; 28(3):578-97. [PubMed: 19217678]

Eisenberg, Daniel; Golberstein, Ezra; Hunt, Justin B. Mental Health and Academic Success in College. The B.E. Journal of Economic Analysis \& Policy. 2009; 9(1)

Ettner, Susan L.; Frank, Richard G.; Kessler, Ronald C. Impact of Psychiatric Disorder on Labor Market Outcomes. Industrial and Labor Relations Review. 1997; 51(1):64-81.

Fletcher, Jason M. Adolescent Depression: Diagnosis, Treatment, and Educational Attainment. Health Economics. 2008; 17(11):1215-35. [PubMed: 18157910]

Gibbons, Robert D.; Hendricks Brown, C.; Hur, Kwan; Marcus, Sue M.; Bhaumik, Dsulal K.; Erkens, Joelle A.; Herings, Ron M.C.; John Mann, J. Early Evidence on the Effects of Regulators' Suicidality Warnings on Ssri Prescriptions and Suicide in Children and Adolescents. American Journal of Psychiatry. 2007; 164(9):1356-63. [PubMed: 17728420]

Glantz, Meyer D. Introduction to the Special Issue on the Impact of Childhood Psychopathology Interventions on Subsequent Substance Abuse: Pieces of the Puzzle. Journal of Consulting and Clinical Psychology. 2002; 70(6):1203-06. [PubMed: 12472297]

Heckman, James J.; Stixrud, Jora; Urzua, Sergio. The Effects of Cognitive and Noncognitive Abilities on Labor Market Outcomes and Social Behavior. Journal of Labor Economics. 2006; 24(3):41182 .

J Hum Resour. Author manuscript; available in PMC 2015 July 01. 
Jane-Llopis, Eva; Matytsina, Irina. Mental Health and Alcohol, Drugs and Tobacco: A Review of the Comorbidity between Mental Disorders and the Use of Alcohol, Tobacco and Illicit Drugs. Drug and Alcohol Review. 2006; 25(6):515-36. [PubMed: 17132571]

Kurian, Benji T.; Ray, Wayne A.; Arbogast, Patrick G.; Catherine Fuchs, D.; Dudley, Judith A.; Cooper, William O. Effect of Regulatory Warnings on Antidepressant Prescribing for Children and Adolescents. Archives of Pediatrics \& Adolescent Medicine. 2007; 161(7):690-96. [PubMed: 17606833]

Libby, Anne M.; Brent, David A.; Morrato, Elaine H.; Orton, Healther D.; Allen, Richard; Valuck, Robert J. Decline in Treatment of Pediatric Depression after FDA Advisory on Risk of Suicidality with SSRIs. American Journal of Psychiatry. 2007; 164(6):884-91. [PubMed: 17541047]

Marcotte, Dave E.; Markowitz, Sara. A Cure for Crime? Psycho-Pharmaceuticals and Crime Trends. Journal of Policy Analysis and Management. 2011; 30(1):29-56. [PubMed: 21465827]

Marsh, Wendy K.; Deligiannidis, Kristina M. Sex-Related Differences in Antidepressant Response: When to Adjust Treatment. Current Psychiatry. 2010; 9(5):25-30.

Merikangas, Kathleen Ries; He, Jian-ping; Burstein, Marcy; Swanson, Sonja A.; Avenevoli, Shelli; Cui, Lihong; Benjet, Corina; Georgiades, Katholiki; Swendsen, Joel. Lifetime Prevalence of Mental Disorders in U.S. Adolescents: Results from the National Comorbidity Survey Replication--Adolescent Supplement (NCS-A). Journal of the American Academy of Child and Adolescent Psychiatry. 2010; 49(10):980-89. [PubMed: 20855043]

Nemeroff, Charles B.; Kalali, Amir; Keller, Martin B.; Charney, Dennis S.; Lenderts, Susan E.; Cascade, Elisa F.; Stephenson, Hugo; Schatzberg, Alan F. Impact of Publicity Concerning Pediatric Suicidality Data on Physician Practice Patterns in the United States. Archives of General Psychiatry. 2007; 64(4):466-72. [PubMed: 17404123]

Olfson, Mark; Marcus, Steven C.; Druss, Benjamin G. Effects of Food and Drug Administration Warnings on Antidepressant Use in a National Sample. Archives of General Psychiatry. 2008; 65(1):94-101. [PubMed: 18180433]

Olfson, Mark; Marcus, Steven C.; Druss, Benjamin G.; Elinson, Lynn; Tanielian, Terri; Pincus, Harold A. National Trends in the Outpatient Treatment of Depression. Journal of the American Medical Association. 2002; 287(2):203-09. [PubMed: 11779262]

Olfson, Mark; Marcus, Steven C.; Weissman, Myrna M.; Jensen, Peter S. National Trends in the Use of Psychotropic Medications by Children. Journal of the American Academy of Child Psychiatry. 2002; 41(5):514-21.

Rosack, Jim. New Data Show Declines in Antidepressant Prescribing. Psychiatric News. 2005; 40(17): 1.

Rosenthal, Meredith B.; Berndt, Ernst R.; Donohue, Julie M.; Frank, Richard G.; Epstein, Arnold M. Promotion of Prescription Drugs to Consumers. New England Journal of Medicine. 2002; 346(7): 498-505. [PubMed: 11844852]

Substance Abuse and Mental Health Services Administration (SAMHSA). Depression and the Initiation of Alcohol and Other Drug Use among Youths Aged 12 to 17. The NSDUH Report. May. 2007; 3:2007.

Swendsen, Joel; Conway, Kevin P.; Degenhardt, Louisa; Glantz, Myer C.; Jin, Robert; Merikangas, Kathleen R.; Sampson, Nancy; Kessler, Ronald C. Mental Disorders as Risk Factors for Substance Use, Abuse and Dependence: Results from the 10-Year Follow-up of the National Comorbidity Survey. Addiction. 2010; 105(6):1117-28. [PubMed: 20331554]

Thase, Michael E.; Entsuah, Richard; Cantillon, Marc; Kornstein, Susan G. Relative Antidepressant Efficacy of Venlafaxine and SSRIs: Sex-Age Interactions. Journal of Women's Health. 2005; 14(7):609-16.

Thomas, Cindy Parks; Conrad, Peter; Casler, Rosemary; Goodman, Elizabeth. Trends in the Use of Psychotropic Drugs among Adolescents, 1994-2001. Psychiatric Services. 2006; 57(1):63-69. [PubMed: 16399964]

Treatment for Adolescents With Depression Study Team. Fluoxetine, Cognitive-Behavioral Therapy, and Their Combination for Adolescents with Depression: Treatment for Adolescents with Depression Study (TADS) Randomized Controlled Trial. Journal of the American Medical Association. 2004; 292(7):807-20. [PubMed: 15315995] 
Valluri, Satish; Zito, Julie M.; Safer, Daniel J.; Zuckerman, Ilene H.; Daniel Mullins, C.; Korelitz, James J. Impact of the 2004 Food and Drug Administration Pediatric Suicidality Warning on Antidepressant and Psychotherapy Treatment for New-Onset Depression. Medical Care. 2010; 48(11):947-54. [PubMed: 20856141]

Young, Elizabeth A.; Kornstein, Susan G.; Marcus, Sheila M.; Harvey, Anne T.; Warden, Diane; Wisniewski, Stephen R.; Balasubramani, GK.; Fava, Maurizio; Trivedi, Madhukar A.; Rush, John A. Sex Differences in Response to Citalopram: A STAR*D Report. Journal of Psychiatric Research. 2009; 43(5):503-11. [PubMed: 18752809] 


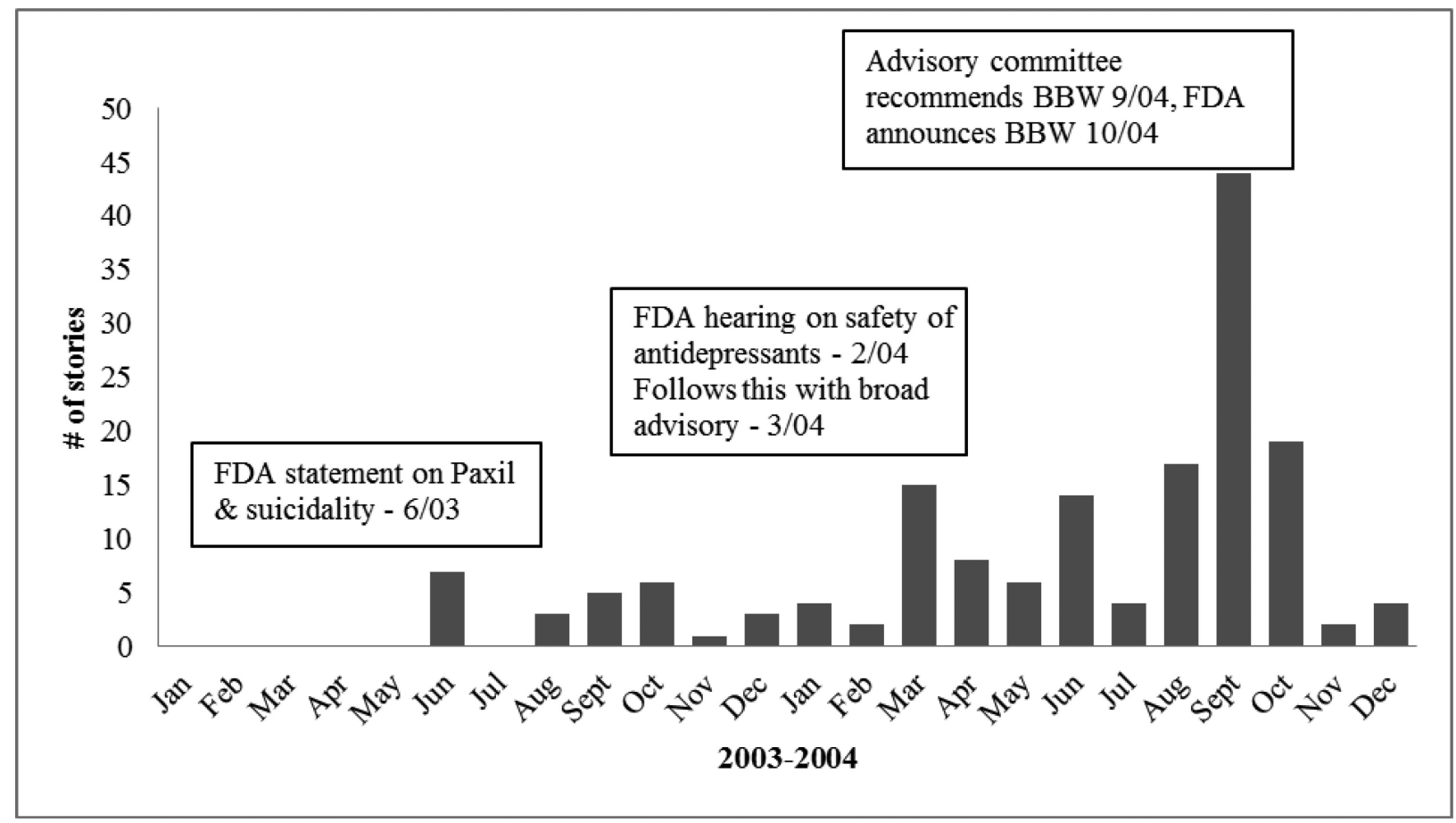

Figure 1. Timeline of FDA Actions \& Counts of News Media Stories on Pediatric Antidepressant Use and Suicidality (2003-2004)

Notes: FDA=Food and Drug Administration. This data was originally displayed in Barry and Busch (2010). Data reflects counts and timing of all news stories on pediatric antidepressant use and suicidality in 10 high circulation print newspapers and three major television networks and CNN from 1/2003-12/2004. 


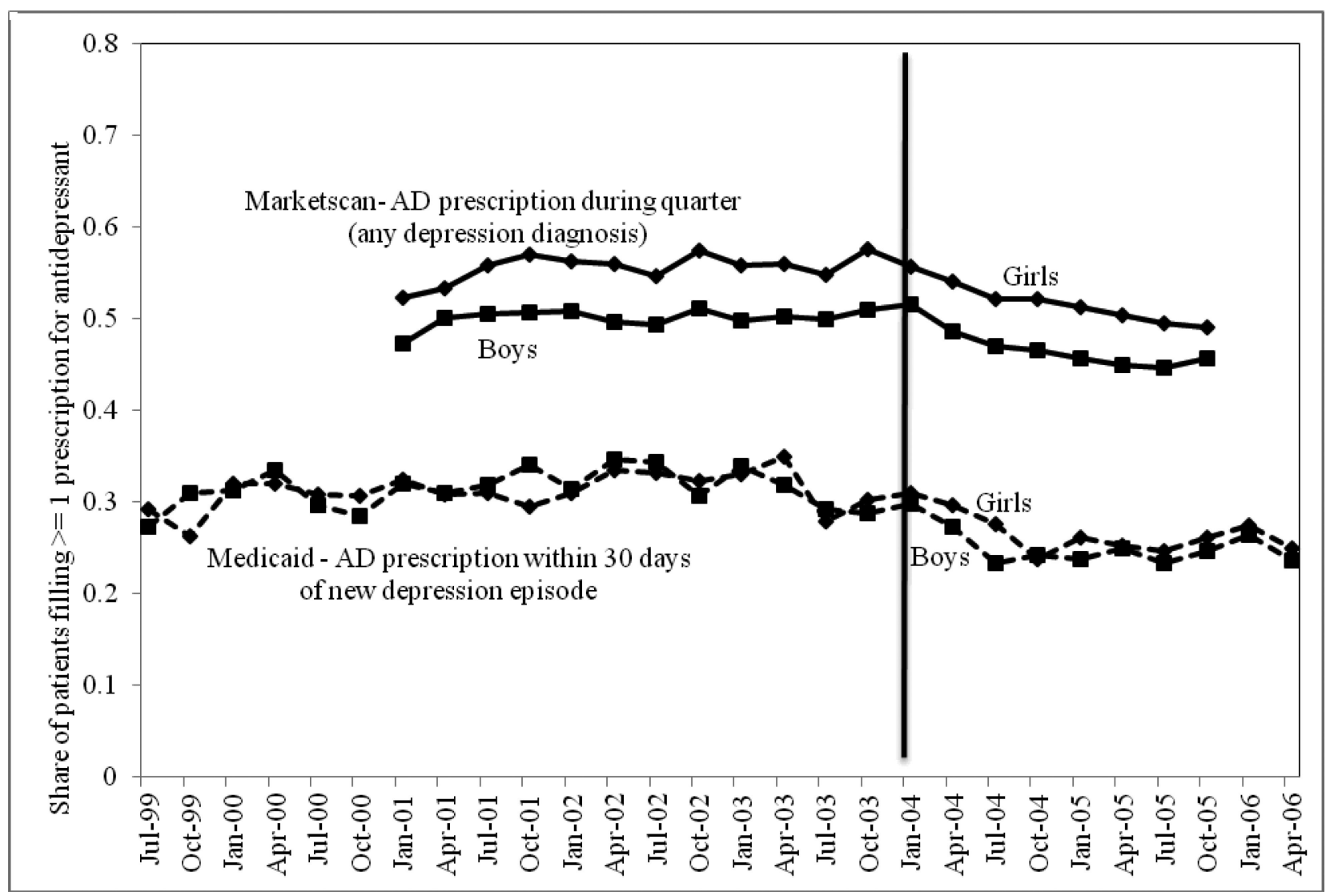

Figure 2. Declines in Antidepressant Use among Privately and Publicly Insured Pediatric Patients Age 12-17

Note: Medicaid data reflect pediatric patients with a diagnosis of depression in the Florida Medicaid program. Marketscan data reflect privately insured pediatric patients with a diagnosis of depression. Antidepressant use is defined as a claim for any one of 36 antidepressants. See text for full details. 


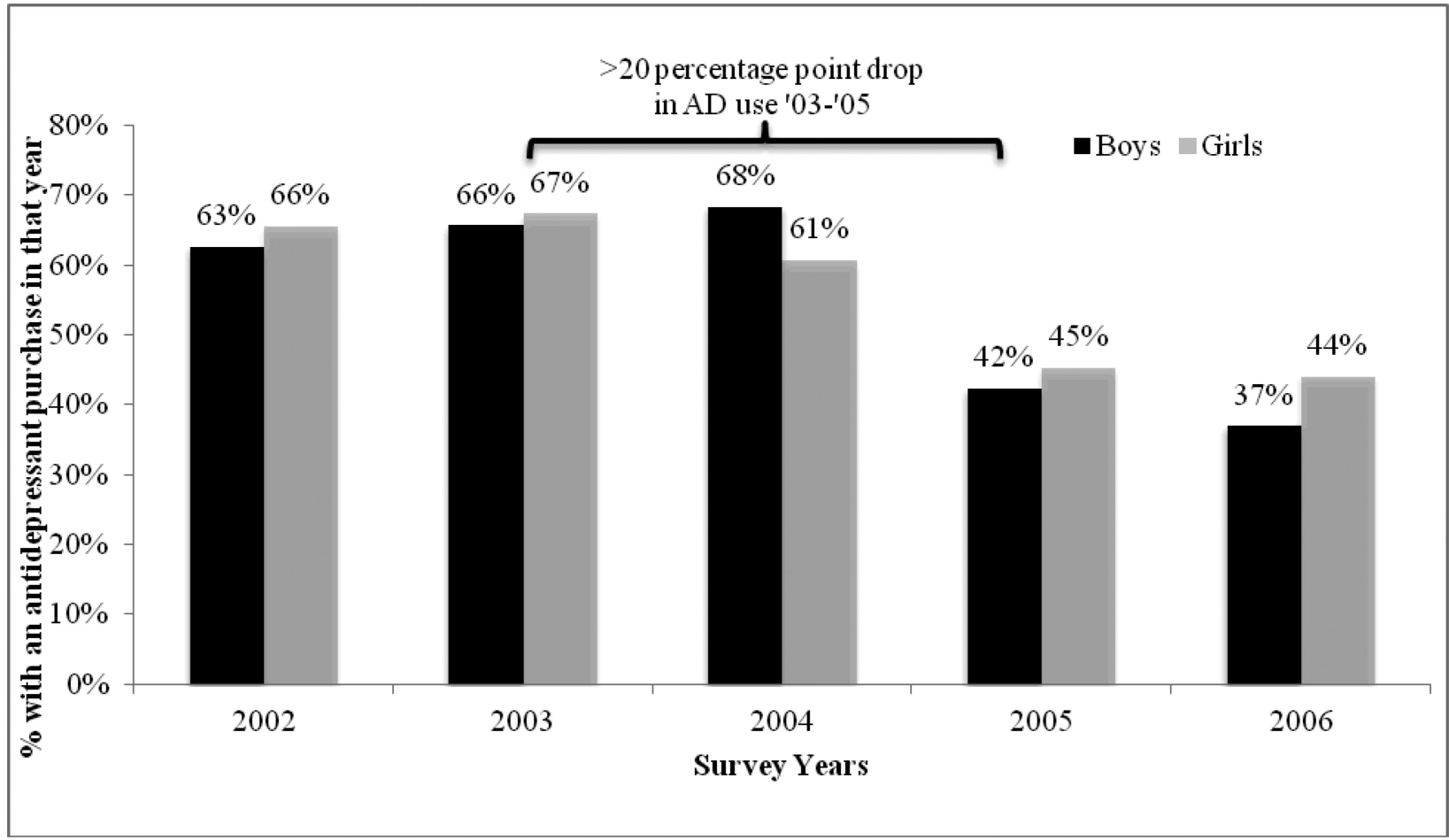

Figure 3. Annual Antidepressant Use among Kids 12-17 Seeing a Medical Provider for Depression Symptoms

Note: Reflects Medical Expenditure Panel Survey data on 12 month prevalence of any antidepressant claim during that calendar year for respondents with a medical encounter including a three-digit International Classification of Disease Code of 296, 300, or 311. Data for 2004 reflect a mix of pre- and post- period data. 


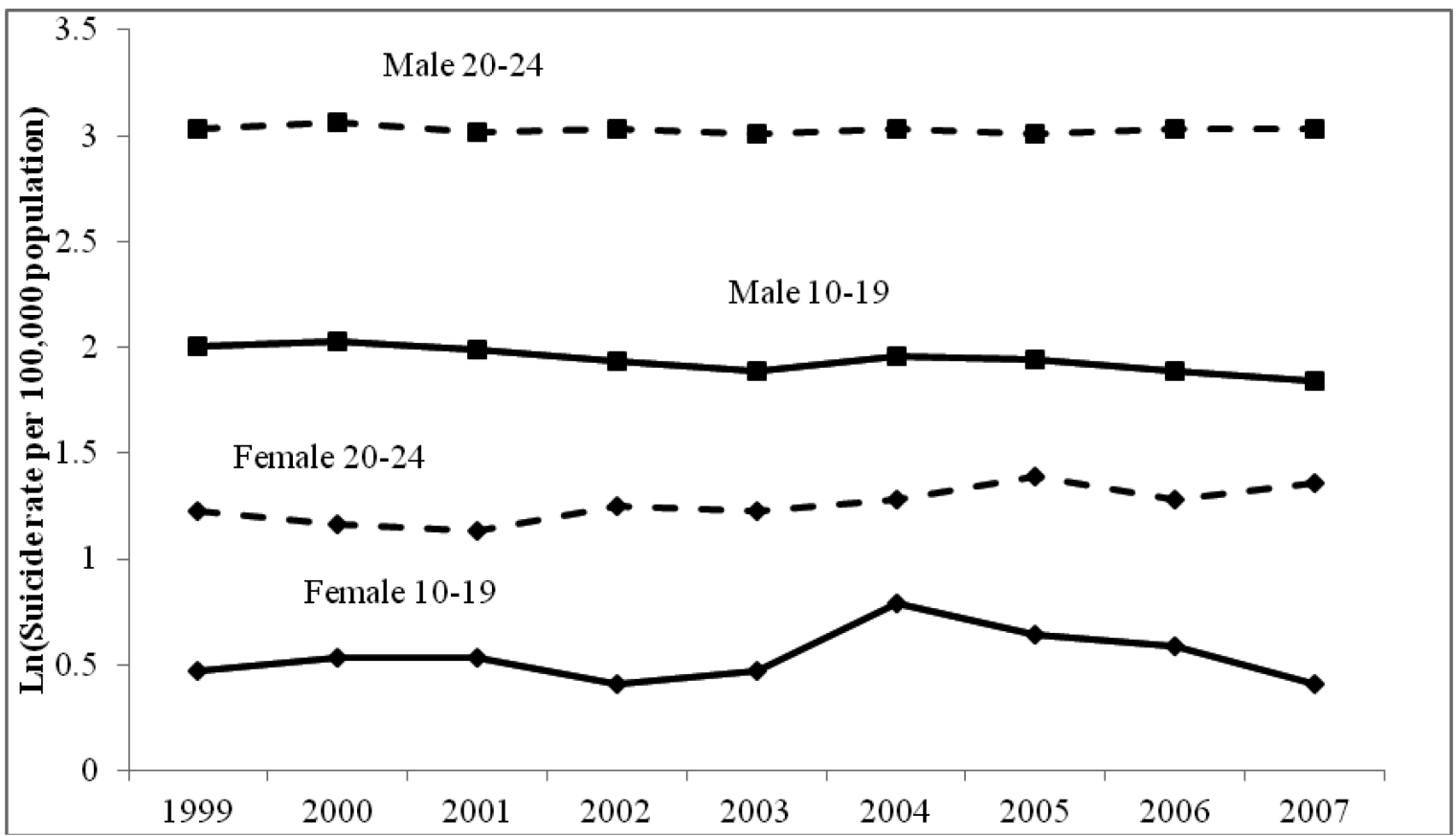

Figure 4. Suicides by Age and Sex

Source: Compiled from Compressed Mortality File 1999-2007 Series 20 No. 2M (Centers for Disease Control and Prevention, National Center for Health Statistics, Compressed Mortality File on CDC WONDER Online Database 2010). 

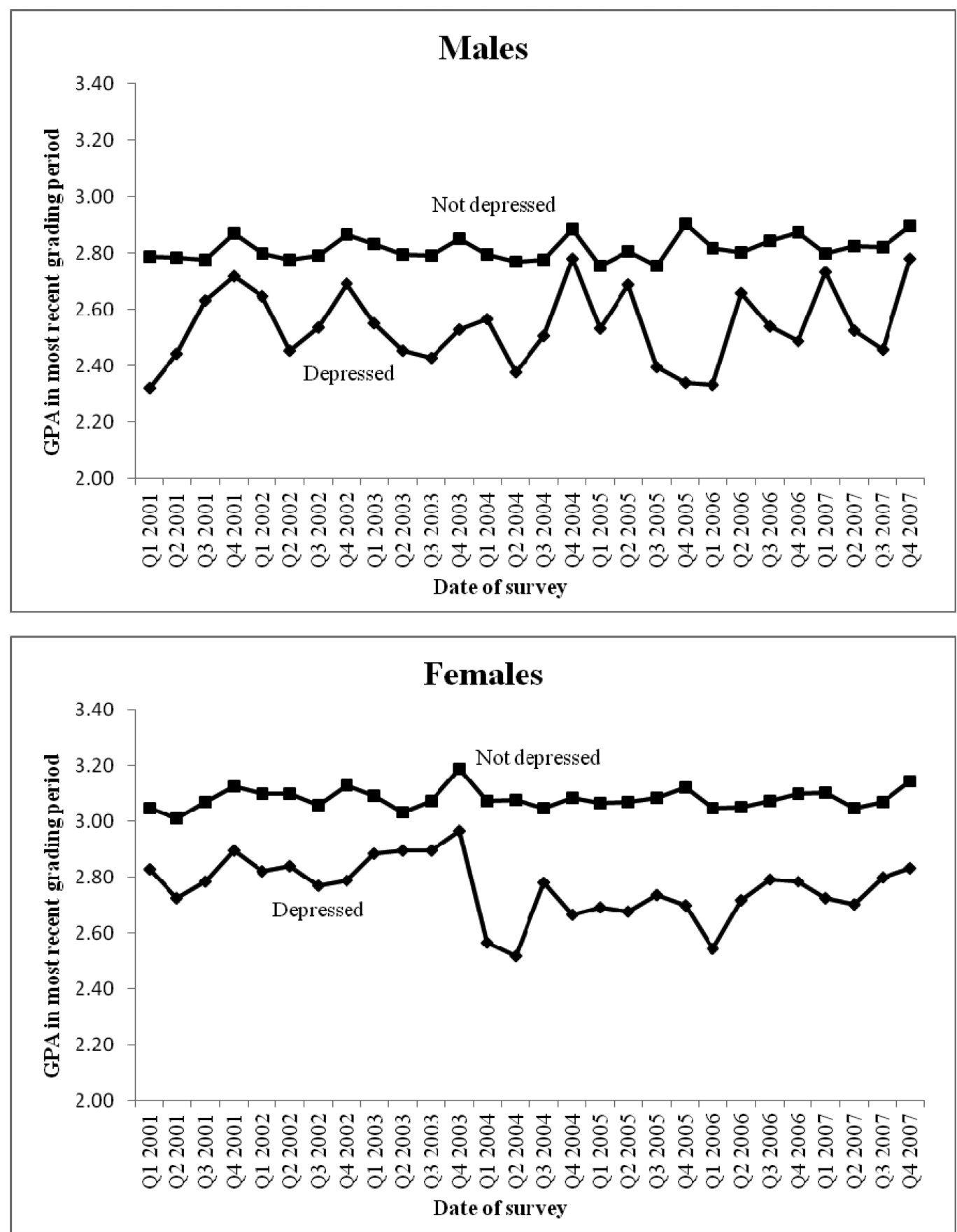

Figure 5. Raw Data on Grade Point Average by Depression Status in Last Year, by Sex Note: $\mathrm{N}=56340$ (males), $\mathrm{N}=54278$ (females), means estimated with NSDUH sampling weights 


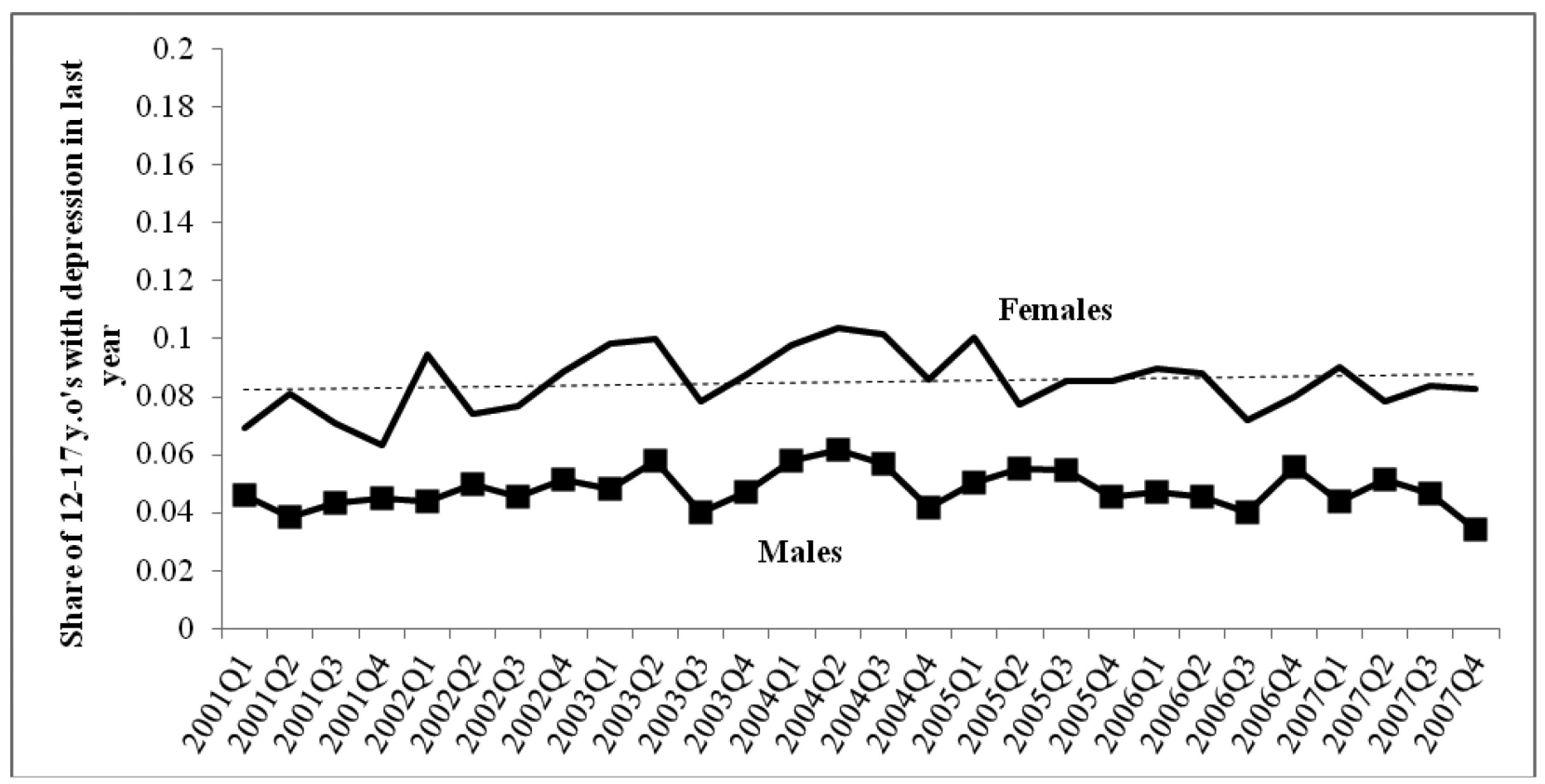

Figure 6. Depression Status Over Time in the NSDUH

Note: A linear probability model of the quarterly rate of depression on a quarterly time trend and an indicator for post-FDA advisories (after Q1 of 2004), yields coefficients (robust standard errors clustered on the time period) on post-FDA of $0.0075(0.008)$ for females and $0.0091(0.005)$ for males. For females, the coefficient on time is $-0.0001(0.0005)$. For males, the coefficient on time is -0.0004 (0.0003). All models are adjusted for seasonality and sociodemographic characteristics (as described by the specification in Table 3 ). In other results (not shown), the overall sociodemographic composition of the sample is generally consistent over time, with only small increases in the proportion Hispanic and with household income over $\$ 75,000$ in the post-period. 


\section{Table 1}

Sample Characteristics by Sex and Depression Status

\begin{tabular}{|c|c|c|c|c|c|}
\hline \multirow{4}{*}{$\begin{array}{l}\text { Not depressed } \\
\text { Depressed }\end{array}$} & \multirow{4}{*}{$\begin{array}{c}\text { All } \\
0.934 \\
0.066 \\
\text { All } \mathbf{n}=\mathbf{1 2 6 , 3 5 5}\end{array}$} & \multirow{2}{*}{\multicolumn{2}{|c|}{$\begin{array}{l}\text { Males } \\
0.952\end{array}$}} & \multirow{2}{*}{\multicolumn{2}{|c|}{$\begin{array}{c}\text { Females } \\
0.915\end{array}$}} \\
\hline & & & & & \\
\hline & & \multicolumn{2}{|r|}{0.048} & \multicolumn{2}{|r|}{0.085} \\
\hline & & Depressed $n=3,203$ & Non- depressed $n=61,292$ & Depressed n=5,686 & Non- depressed $n=56,174$ \\
\hline \multicolumn{6}{|l|}{ Age } \\
\hline 12 & 0.159 & 0.145 & 0.158 & 0.083 & 0.169 \\
\hline 13 & 0.169 & 0.169 & 0.172 & 0.131 & 0.169 \\
\hline 14 & 0.170 & 0.159 & 0.171 & 0.168 & 0.171 \\
\hline 15 & 0.171 & 0.174 & 0.170 & 0.209 & 0.169 \\
\hline 16 & 0.167 & 0.165 & 0.167 & 0.208 & 0.165 \\
\hline 17 & 0.163 & 0.188 & 0.163 & 0.201 & 0.158 \\
\hline \multicolumn{6}{|l|}{ Quarter } \\
\hline 1 & 0.244 & 0.244 & 0.243 & 0.264 & 0.244 \\
\hline 2 & 0.253 & 0.270 & 0.251 & 0.255 & 0.253 \\
\hline 3 & 0.253 & 0.247 & 0.254 & 0.240 & 0.253 \\
\hline 4 & 0.250 & 0.239 & 0.252 & 0.240 & 0.250 \\
\hline \multicolumn{6}{|l|}{ Race/ethnicity } \\
\hline White & 0.617 & 0.683 & 0.616 & 0.688 & 0.607 \\
\hline Black & 0.150 & 0.141 & 0.148 & 0.117 & 0.155 \\
\hline Native American & 0.007 & 0.007 & 0.007 & 0.011 & 0.006 \\
\hline \multicolumn{6}{|l|}{ Hawaiian/Pacific } \\
\hline Islander & 0.003 & 0.002 & 0.003 & 0.002 & 0.004 \\
\hline Asian & 0.040 & 0.020 & 0.041 & 0.017 & 0.042 \\
\hline Multiple & 0.016 & 0.019 & 0.015 & 0.021 & 0.017 \\
\hline Hispanic & 0.168 & 0.127 & 0.170 & 0.144 & 0.169 \\
\hline \multicolumn{6}{|l|}{ Family income } \\
\hline under $\$ 10,000$ & 0.058 & 0.075 & 0.056 & 0.064 & 0.060 \\
\hline$\$ 10,000$ - \$19,999 & 0.117 & 0.125 & 0.113 & 0.132 & 0.121 \\
\hline$\$ 20,000-\$ 29,999$ & 0.113 & 0.117 & 0.112 & 0.109 & 0.114 \\
\hline$\$ 30,000-\$ 39,999$ & 0.113 & 0.108 & 0.114 & 0.115 & 0.113 \\
\hline$\$ 40,000$ - $\$ 49,999$ & 0.113 & 0.112 & 0.114 & 0.108 & 0.114 \\
\hline$\$ 50,000-\$ 75,000$ & 0.192 & 0.189 & 0.193 & 0.189 & 0.190 \\
\hline over $\$ 75,000$ & 0.293 & 0.274 & 0.298 & 0.282 & 0.289 \\
\hline
\end{tabular}

Notes: All means and proportions are estimated with the NSDUH sampling weights and include all non-missing observations in the 2001-2007 NSDUH.

J Hum Resour. Author manuscript; available in PMC 2015 July 01. 
Table 2

Outcome Variables by Sex \& Depression Status

\begin{tabular}{|c|c|c|c|c|c|}
\hline & \multirow[b]{2}{*}{ All } & \multicolumn{2}{|c|}{ Males } & \multicolumn{2}{|c|}{ Females } \\
\hline & & Depressed & Non- depressed & Depressed & Non- depressed \\
\hline GPA & $2.924(0.878)$ & $2.534(0.944)$ & $2.815(0.887)$ & $2.756(0.904)$ & $3.080(0.834)$ \\
\hline Grades $=\mathrm{A}$ & 0.285 & 0.165 & 0.239 & 0.216 & 0.347 \\
\hline Grades $=B$ & 0.420 & 0.359 & 0.415 & 0.425 & 0.429 \\
\hline Grades $=\mathrm{C}$ & 0.229 & 0.321 & 0.267 & 0.258 & 0.181 \\
\hline Grades $=\mathrm{D} / \mathrm{F}$ & 0.066 & 0.156 & 0.079 & 0.101 & 0.044 \\
\hline \multicolumn{6}{|c|}{ Fights in past 12 months } \\
\hline 0 times & 0.778 & 0.576 & 0.749 & 0.662 & 0.831 \\
\hline 1-2 times & 0.171 & 0.290 & 0.192 & 0.242 & 0.135 \\
\hline 3-5 times & 0.034 & 0.083 & 0.038 & 0.060 & 0.024 \\
\hline 6-9 times & 0.008 & 0.023 & 0.009 & 0.019 & 0.005 \\
\hline $10+$ times & 0.009 & 0.028 & 0.012 & 0.018 & 0.005 \\
\hline \multicolumn{6}{|c|}{ Stole in past 12 months } \\
\hline 0 times & 0.955 & 0.851 & 0.947 & 0.898 & 0.974 \\
\hline 1-2 times & 0.032 & 0.099 & 0.038 & 0.067 & 0.019 \\
\hline 3-5 times & 0.006 & 0.022 & 0.008 & 0.015 & 0.004 \\
\hline 6-9 times & 0.003 & 0.009 & 0.002 & 0.009 & 0.002 \\
\hline $10+$ times & 0.004 & 0.020 & 0.005 & 0.011 & 0.002 \\
\hline \multicolumn{6}{|c|}{ Attacked anyone in past 12 months } \\
\hline 0 times & 0.921 & 0.774 & 0.909 & 0.849 & 0.950 \\
\hline $1-2$ times & 0.064 & 0.163 & 0.074 & 0.115 & 0.043 \\
\hline 3-5 times & 0.009 & 0.035 & 0.011 & 0.024 & 0.005 \\
\hline 6-9 times & 0.003 & 0.012 & 0.003 & 0.006 & 0.001 \\
\hline $10+$ times & 0.003 & 0.016 & 0.004 & 0.006 & 0.001 \\
\hline \multicolumn{6}{|c|}{ Substance Use in past 30 days } \\
\hline Any binge drinking & 0.105 & 0.162 & 0.108 & 0.189 & 0.091 \\
\hline Any cigarette use & 0.116 & 0.214 & 0.108 & 0.260 & 0.107 \\
\hline Any illicit drug use & 0.105 & 0.220 & 0.092 & 0.208 & 0.102 \\
\hline \multicolumn{6}{|l|}{ Any nonmedical Rx } \\
\hline drug use & 0.035 & 0.079 & 0.029 & 0.088 & 0.034 \\
\hline
\end{tabular}

J Hum Resour. Author manuscript; available in PMC 2015 July 01. 
Table 3

Difference-in-difference OLS Models of Grades

\begin{tabular}{|c|c|c|c|}
\hline & All Coefficient(Standard Error) & $\begin{array}{c}\text { Females Coefficient (Standard } \\
\text { Error) }\end{array}$ & $\begin{array}{l}\text { Males Coefficient (Standard } \\
\text { Error) }\end{array}$ \\
\hline Post-FDA*Depressed & $-0.142 * * *(0.046)$ & $-0.203^{* * *}(0.052)$ & $-0.030(0.094)$ \\
\hline Depressed & $-0.284 * * *(0.023)$ & $-0.296 * * *(0.024)$ & $-0.277^{* * *}(0.060)$ \\
\hline Post-FDA & $-0.026^{*}(0.014)$ & $0.003(0.026)$ & $-0.055^{*}(0.027)$ \\
\hline Time & $0.002 * *(0.001)$ & $0.004 * * *(0.002)$ & $0.001(0.002)$ \\
\hline Time*Post-FDA & $-0.001(0.001)$ & $-0.004 *(0.002)$ & $0.002(0.002)$ \\
\hline Time*Depressed & $0.006 * *(0.003)$ & $0.008 * *(0.003)$ & $0.002(0.006)$ \\
\hline Female & $0.268 * * *(0.008)$ & - & - \\
\hline Quarter $=2$ & $-0.002(0.007)$ & $-0.015(0.011)$ & $0.011(0.010)$ \\
\hline Quarter=3 & $0.002(0.007)$ & $0.000(0.008)$ & $0.004(0.012)$ \\
\hline Quarter $=4$ & $0.067 * * *(0.008)$ & $0.046^{* * *}(0.011)$ & $0.088 * * *(0.013)$ \\
\hline Age & $-0.046 * * *(0.002)$ & $-0.038 * * *(0.003)$ & $-0.052 * * *(0.003)$ \\
\hline Race/ethnicity Black & $-0.211 * * *(0.009)$ & $-0.211 * * *(0.012)$ & $-0.212 * * *(0.013)$ \\
\hline Native American & $-0.156^{* * *}(0.051)$ & $-0.071(0.085)$ & $-0.234 * * *(0.051)$ \\
\hline Hawaiian/Pacific Islander & $-0.212 * * *(0.073)$ & $-0.288 * * *(0.086)$ & $-0.124(0.131)$ \\
\hline Asian & $0.292 * * *(0.025)$ & $0.299 * * *(0.026)$ & $0.284 * * *(0.041)$ \\
\hline Multiple race & $-0.135 * * *(0.032)$ & $-0.150 * * *(0.045)$ & $-0.120 * * *(0.039)$ \\
\hline \multirow[t]{2}{*}{ Hispanic } & -0.156 & -0.172 & -0.141 \\
\hline & $(0.009)$ & $(0.014)$ & $(0.013)$ \\
\hline \multicolumn{4}{|l|}{ Family Income } \\
\hline$\$ 10,000-\$ 19,999$ & $0.015(0.017)$ & $0.022(0.026)$ & $0.010(0.024)$ \\
\hline$\$ 20,000-\$ 29,999$ & $0.058 * * *(0.018)$ & $0.068 * *(0.027)$ & $0.049 * *(0.023)$ \\
\hline$\$ 30,000-\$ 39,999$ & $0.112 * * *(0.018)$ & $0.156 * * *(0.025)$ & $0.068 * *(0.024)$ \\
\hline$\$ 40,000-\$ 49,999$ & $0.177 * * *(0.022)$ & $0.201 * * *(0.032)$ & $0.153 * * *(0.026)$ \\
\hline$\$ 50,000-\$ 75,000$ & $0.296^{* * *}(0.020)$ & $0.317 * * *(0.023)$ & $0.277 * * *(0.027)$ \\
\hline$>\$ 75,000$ & $0.467 * * *(0.018)$ & $0.487 * * *(0.022)$ & $0.448 * * *(0.024)$ \\
\hline Constant & $2.748^{* * *}(0.022)$ & $2.978 * * *(0.028)$ & $2.786 * * *(0.028)$ \\
\hline $\mathrm{R}^{2}$ & 0.105 & 0.096 & 0.079 \\
\hline $\mathrm{N}$ & 106,639 & 52,287 & 54,352 \\
\hline
\end{tabular}

Notes: OLS models estimated with heteroskedasticity-robust standard errors clustered on the time period. Observations from the first quarter of 2004 are excluded from the models. 
Table 4

Effects of FDA Warnings at Different Points in the Grade Distribution

\begin{tabular}{lccc}
\hline & All & Females & Males \\
& Coefficient (Standard Error) & Coefficient (Standard Error) & Coefficient (Standard Error) \\
\hline Dependent Variable & & & \\
A average & $-0.020(0.021)$ & $-0.018(0.027)$ & $-0.029(0.044)$ \\
B average or better & $-0.084^{* * *}(0.029)$ & $-0.112^{* * *}(0.037)$ & $-0.026(0.047)$ \\
C average or better & $-0.035^{*}(0.019)$ & $-0.059^{* * *}(0.016)$ & $0.027(0.032)$ \\
$\mathrm{N}$ & 106,639 & 52,287 & 54,352 \\
\hline
\end{tabular}

Notes: Each cell represents the marginal effect and bootstrapped standard error from a separate probit model. Standard errors estimated from 500 bootstrap replications clustered on time period. All models exclude observations from first quarter of 2004. All models include the same set of covariates in Table 3. 


\section{Table 5}

Effects of FDA Warnings on Substance Use

\begin{tabular}{|c|c|c|c|}
\hline & \multicolumn{3}{|c|}{ Any Binge Drinking, Past 30 days } \\
\hline & All Coefficient (Standard Error) & Females Coefficient (Standard Error) & Males Coefficient (Standard Error) \\
\hline Post-FDA*Depressed & $-0.062(0.112)$ & $0.038(0.105)$ & $-0.262(0.205)$ \\
\hline Marginal Effect & $-0.014(0.025)$ & $0.009(0.023)$ & $-0.055(0.043)$ \\
\hline Depressed & $0.272 * * *(0.045)$ & $0.331 * * *(0.039)$ & $0.184 * *(0.087)$ \\
\hline Marginal Effect & $0.058^{* * *}(0.004)$ & $0.066^{* * * *}(0.005)$ & $0.046^{* * * *}(0.007)$ \\
\hline Post-FDA & $0.079 * *(0.038)$ & $0.110 * *(0.049)$ & $0.051(0.047)$ \\
\hline Marginal Effect & $0.000(0.006)$ & $0.003(0.003)$ & $-0.003(0.012)$ \\
\hline $\mathrm{N}$ & 121,785 & 59,589 & 62,196 \\
\hline \multirow[t]{3}{*}{ Pseudo- $\mathrm{R}^{2}$} & 0.132 & 0.114 & 0.151 \\
\hline & \multicolumn{3}{|c|}{ Any Cigarette Use, Past 30 days } \\
\hline & All Coefficient (Standard Error) & Females Coefficient (Standard Error) & Males Coefficient (Standard Error) \\
\hline Post-FDA*Depressed & $0.190^{* * *}(0.056)$ & $0.187(0.114)$ & $0.164(0.156)$ \\
\hline Marginal Effect & $0.0459 * * *(0.016)$ & $0.050(0.034)$ & $0.035(0.038)$ \\
\hline Depressed & $0.513^{* * *}(0.029)$ & $0.557 * * *(0.050)$ & $0.409 * * *(0.054)$ \\
\hline Marginal Effect & $0.102 * * *(0.004)$ & $0.110 * * *(0.007)$ & $0.090 * * *(0.007)$ \\
\hline Post-FDA & $0.044(0.048)$ & $0.090(0.062)$ & $0.002(0.058)$ \\
\hline Marginal Effect & $-0.003(0.007)$ & $0.005(0.006)$ & $-0.011(0.007)$ \\
\hline Pseudo- $\mathrm{R}^{2}$ & 0.135 & 0.134 & 0.139 \\
\hline \multirow[t]{4}{*}{$\mathrm{N}$} & 121,785 & 59,589 & 62,196 \\
\hline & \multicolumn{3}{|c|}{ Illicit Drug Use, Past 30 days } \\
\hline & All & Females & Males \\
\hline & Coefficient (Standard Error) & Coefficient (Standard Error) & Coefficient (Standard Error) \\
\hline Post-FDA*Depressed & $0.186 * *(0.079)$ & $0.228 * *(0.105)$ & $0.097(0.099)$ \\
\hline Marginal Effect & $0.04027 *(0.023)$ & $0.0542 *(0.031)$ & $-0.031(0.030)$ \\
\hline Depressed & $0491 * * *(0.045)$ & $0.560 * * *(0.044)$ & $0.397 * * *(0.096)$ \\
\hline Marginal Effect & $0.101(0.005)$ & $0.103 * * *(0.007)$ & $0.098 * * *(0.008)$ \\
\hline Post-FDA & $0.023(0.035)$ & $0.071(0.055)$ & $-0.022(0.054)$ \\
\hline Marginal Effect & $-0.016(0.007)$ & $-0.012(0.009)$ & $-0.021 * *(0.009)$ \\
\hline Pseudo- $\mathrm{R}^{2}$ & 0.071 & 0.065 & 0.079 \\
\hline \multirow[t]{3}{*}{$\mathrm{N}$} & 121,785 & 59,589 & 62,196 \\
\hline & \multicolumn{3}{|c|}{ Nonmedical Rx Drug Use, Past 30 days } \\
\hline & All Coefficient (Standard Error) & $\begin{array}{c}\text { Females Coefficient ( Standard } \\
\text { Error) }\end{array}$ & Males Coefficient (Standard Error) \\
\hline Post-FDA*Depressed & $0.172(0.129)$ & $0.331 * *(0.143)$ & $-0.102(0.185)$ \\
\hline Marginal Effect & $0.018(0.020)$ & $0.0427 *(0.024)$ & $-0.029(0.044)$ \\
\hline Depressed & $0.490 * * *(0.057)$ & $0.519 * * *(0.068)$ & $0.434 * * *(0.103)$ \\
\hline Marginal Effect & $0.0437 * * *(0.004)$ & $0.0434 * * *(0.005)$ & $0.047 * * *(0.007)$ \\
\hline Post-FDA & $0.087 *(0.048)$ & $0.026(0.087)$ & $0.152 * *(0.077)$ \\
\hline Marginal Effect & $-0.011^{*}(0.006)$ & $-0.009(0.012)$ & $-0.014(0.009)$ \\
\hline
\end{tabular}




\begin{tabular}{lccc}
\hline & & Any Binge Drinking, Past 30 days & \\
& All Coefficient (Standard Error) & Females Coefficient (Standard Error) & Males Coefficient (Standard Error) \\
\hline Pseudo- $\mathrm{R}^{2}$ & 0.041 & 0.040 & 0.043 \\
$\mathrm{~N}$ & 121,785 & 59,589 & 62,196 \\
\hline
\end{tabular}

Notes: All models exclude observations from first quarter of 2004. Standard errors of marginal effects are estimated from 500 bootstrap replications, clustered on the time period. All models include the same set of covariates in Table 3.

$* \mathrm{p}<0.10$,

$* * \mathrm{p}<0.05$,

$* * * \mathrm{p}<0.01$ 
Table 6

Effects of FDA Warnings on Delinquency Outcomes, Probit Models

\begin{tabular}{|c|c|c|c|}
\hline & \multicolumn{3}{|c|}{ Fights past 12 months } \\
\hline & All Coefficient (Standard Error) & Females Coefficient (Standard Error) & Males Coefficient (Standard Error) \\
\hline \multirow[t]{2}{*}{ Post-FDA*Depressed } & $0.187 * * *$ & $0.236^{* * *}$ & 0.155 \\
\hline & $(0.054)$ & $(0.071)$ & $(0.124)$ \\
\hline \multirow[t]{2}{*}{ Marginal Effect } & $0.065^{* * *}$ & $0.075^{* * *}$ & 0.045 \\
\hline & $(0.025)$ & $(0.027)$ & $(0.043)$ \\
\hline \multirow[t]{2}{*}{ Depressed } & $0.589^{* * *}$ & $0.668 * * *$ & $0.488^{* * *}$ \\
\hline & $(0.051)$ & $(0.059)$ & $(0.075)$ \\
\hline \multirow[t]{2}{*}{ Marginal Effect } & $0.177 * * *$ & $0.175^{* * *}$ & $0.170^{* * *}$ \\
\hline & $(0.007)$ & $(0.009)$ & $(0.011)$ \\
\hline \multirow[t]{2}{*}{ Post-FDA } & $0.205^{* * *}$ & $0.127^{* * *}$ & $0.266^{* * *}$ \\
\hline & $(0.031)$ & $(0.032)$ & $(0.040)$ \\
\hline \multirow[t]{2}{*}{ Marginal Effect } & $-0.032 * *$ & $-0.038 * *$ & -0.024 \\
\hline & $(0.015)$ & $(0.017)$ & $(0.020)$ \\
\hline Pseudo- $R^{2}$ & 0.0348 & 0.0356 & 0.0219 \\
\hline $\mathrm{N}$ & 116,371 & 57,030 & 59,341 \\
\hline Stealing past 12 months & s All Coefficient (Standard Error) & $\begin{array}{l}\text { Females Coefficient (Standard } \\
\text { Error) }\end{array}$ & $\begin{array}{l}\text { Males Coefficient (Standard } \\
\text { Error) }\end{array}$ \\
\hline \multirow[t]{2}{*}{ Post-FDA*Depressed } & $0.263 * *$ & $0.445^{* * *}$ & -0.006 \\
\hline & $(0.126)$ & $(0.199)$ & $(0.181)$ \\
\hline \multirow[t]{2}{*}{ Marginal Effect } & $0.046^{*}$ & $0.069^{* *}$ & -0.023 \\
\hline & $(0.028)$ & $(0.032)$ & $(0.038)$ \\
\hline \multirow[t]{2}{*}{ Depressed } & $0.673 * * *$ & $0.735^{* * *}$ & $0.587 * * *$ \\
\hline & $(0.055)$ & $(0.090)$ & $(0.084)$ \\
\hline \multirow[t]{2}{*}{ Marginal Effect } & $0.085^{* * *}$ & $0.071^{* * *}$ & $0.098 * * *$ \\
\hline & $(0.005)$ & $(0.006)$ & $(0.010)$ \\
\hline \multirow[t]{2}{*}{ Post-FDA } & 0.009 & -0.015 & 0.020 \\
\hline & $(0.068)$ & $(0.093)$ & $(0.105)$ \\
\hline \multirow[t]{2}{*}{ Marginal Effect } & -0.003 & 0.002 & -0.008 \\
\hline & $(0.006)$ & $(0.004)$ & $(0.009)$ \\
\hline Pseudo-R ${ }^{2}$ & 0.054 & 0.054 & 0.040 \\
\hline \multirow[t]{3}{*}{$\mathrm{N}$} & 116,471 & 57,073 & 59,398 \\
\hline & & Attacks past 12 months & \\
\hline & All Coefficient (Standard Error) & Females Coefficient (Standard Error) & Males Coefficient (Standard Error) \\
\hline \multirow[t]{2}{*}{ Post-FDA*Depressed } & 0.034 & 0.143 & -0.070 \\
\hline & $(0.094)$ & $(0.133)$ & $(0.134)$ \\
\hline \multirow[t]{2}{*}{ Marginal Effect } & 0.0004 & 0.019 & -0.021 \\
\hline & $(0.026)$ & $(0.031)$ & $(0.039)$ \\
\hline Depressed & $0.646^{* * *}$ & $0.697 * * *$ & $0.605 * * *$ \\
\hline
\end{tabular}

J Hum Resour. Author manuscript; available in PMC 2015 July 01. 


\begin{tabular}{lccc}
\hline & All Coefficient (Standard Error) & Females Coefficient (Standard Error) & Males Coefficient (Standard Error) \\
\hline \multirow{2}{*}{ Marginal Effect } & $(0.050)$ & $(0.056)$ & $(0.074)$ \\
& $0.117^{* * *}$ & $0.101^{* * *}$ & $0.133^{* * *}$ \\
Post-FDA & $(0.006)$ & $(0.007)$ & $(0.009)$ \\
& 0.007 & -0.099 & 0.074 \\
Marginal Effect & $(0.054)$ & $(0.085)$ & $(0.055)$ \\
& -0.010 & -0.010 & -0.009 \\
Pseudo-R ${ }^{2}$ & $(0.007)$ & $(0.009)$ & $(0.008)$ \\
$\mathrm{N}$ & 0.046 & 0.054 & 0.027 \\
\hline
\end{tabular}

Notes: All models exclude observations from first and second quarters of 2004. Standard errors of marginal effects are estiamted from 500 bootstrap replications, clustered on the time period. 
Table 7

Specification Check of Coefficients on "Depress*Post-FDA" in OLS Regressions of Covariates

\begin{tabular}{|c|c|c|c|}
\hline & All Coefficient (Standard Error) & Females Coefficient (Standard Error) & Males Coefficient (Standard Error) \\
\hline \multirow[t]{2}{*}{ Age } & -0.008 & 0.076 & -0.115 \\
\hline & $(0.067)$ & $(0.099)$ & $(0.158)$ \\
\hline \multicolumn{4}{|l|}{ Race/ethnicity } \\
\hline \multirow[t]{2}{*}{ Black } & -0.005 & 0.002 & -0.015 \\
\hline & $(0.018)$ & $(0.024)$ & $(0.037)$ \\
\hline \multirow[t]{2}{*}{ Native American } & -0.009 & -0.012 & -0.003 \\
\hline & $(0.006)$ & $(0.010)$ & $(0.004)$ \\
\hline \multicolumn{4}{|l|}{ Hawaiian/Pacific } \\
\hline \multirow[t]{2}{*}{ Islander } & 0.003 & 0.004 & 0.001 \\
\hline & $(0.003)$ & $(0.003)$ & $(0.004)$ \\
\hline \multirow[t]{2}{*}{ Asian } & 0.005 & -0.007 & 0.023 \\
\hline & $(0.012)$ & $(0.011)$ & $(0.026)$ \\
\hline \multirow[t]{2}{*}{ Multiple race } & 0.007 & 0.010 & 0.001 \\
\hline & $(0.006)$ & $(0.006)$ & $(0.012)$ \\
\hline \multirow[t]{2}{*}{ Hispanic } & $0.031 * *$ & 0.031 & 0.032 \\
\hline & $(0.015)$ & $(0.020)$ & $(0.033)$ \\
\hline \multicolumn{4}{|l|}{ Family Income } \\
\hline \multirow[t]{2}{*}{$\$ 10,000-\$ 19,999$} & -0.007 & 0.003 & -0.024 \\
\hline & $(0.027)$ & $(0.023)$ & $(0.043)$ \\
\hline \multirow[t]{2}{*}{$\$ 20,000-\$ 29,999$} & -0.008 & -0.007 & -0.020 \\
\hline & $(0.013)$ & $(0.014)$ & $(0.025)$ \\
\hline \multirow[t]{2}{*}{$\$ 30,000-\$ 39,999$} & 0.004 & 0.023 & -0.030 \\
\hline & $(0.017)$ & $(0.024)$ & $(0.028)$ \\
\hline \multirow[t]{2}{*}{$\$ 40,000-\$ 49,999$} & $0.032 *$ & 0.018 & $0.054 * *$ \\
\hline & $(0.016)$ & $(0.020)$ & $(0.026)$ \\
\hline \multirow[t]{2}{*}{$\$ 50,000-\$ 75,000$} & -0.008 & -0.010 & 0.004 \\
\hline & $(0.023)$ & $(0.024)$ & $(0.049)$ \\
\hline \multirow[t]{2}{*}{$>\$ 75,000$} & -0.030 & -0.036 & -0.013 \\
\hline & $(0.036)$ & $(0.045)$ & $(0.034)$ \\
\hline \multirow[t]{2}{*}{ Female } & -0.017 & - & - \\
\hline & $(0.022)$ & & \\
\hline
\end{tabular}

Each cell shows the coefficient and standard error, from a separate model. The outcome variable in each model is indicated by the row. The other independent variables in the model include dummies for depression, post-FDA, a time trend, the interaction of post-FDA*Time, the interaction of depression*Time, and three indicators for the quarter ( $2 \mathrm{nd}, 3 \mathrm{rd}$, 4 th ) when a respondent completed the survey.

$* \mathrm{p}<0.10$,

** $\mathrm{p}<0.05$,

*** $\mathrm{p}<0.01$. 